Article

\title{
Comparison of Multi-Criteria Decision Support Methods for Integrated Rehabilitation Prioritization
}

\author{
Franz Tscheikner-Gratl *, Patrick Egger, Wolfgang Rauch and Manfred Kleidorfer \\ Unit of Environmental Engineering, University of Innsbruck, Technikerstrasse 13, Innsbruck 6020, Austria; \\ patrick.egger@tbfmartiag.ch (P.E.); Wolfgang.Rauch@uibk.ac.at (W.R.); Manfred.Kleidorfer@uibk.ac.at (M.K.) \\ * Correspondence: Franz.Tscheikner-Gratl@uibk.ac.at; Tel.: +43-512-5076-2118
}

Academic Editor: Gregory L. Leslie

Received: 24 October 2016; Accepted: 17 January 2017; Published: 24 January 2017

\begin{abstract}
The decisions taken in rehabilitation planning for the urban water networks will have a long lasting impact on the functionality and quality of future services provided by urban infrastructure. These decisions can be assisted by different approaches ranging from linear depreciation for estimating the economic value of the network over using a deterioration model to assess the probability of failure or the technical service life to sophisticated multi-criteria decision support systems. Subsequently, the aim of this paper is to compare five available multi-criteria decision-making (MCDM) methods (ELECTRE, AHP, WSM, TOPSIS, and PROMETHEE) for the application in an integrated rehabilitation management scheme for a real world case study and analyze them with respect to their suitability to be used in integrated asset management of water systems. The results of the different methods are not equal. This occurs because the chosen score scales, weights and the resulting distributions of the scores within the criteria do not have the same impact on all the methods. Independently of the method used, the decision maker must be familiar with its strengths but also weaknesses. Therefore, in some cases, it would be rational to use one of the simplest methods. However, to check for consistency and increase the reliability of the results, the application of several methods is encouraged.
\end{abstract}

Keywords: asset management; urban water infrastructure; multi-utility rehabilitation; decision support; ELECTRE; AHP; WSM; TOPSIS; PROMETHEE

\section{Introduction}

Urban water management addresses all water-related issues in urban agglomerations. Its functioning is crucial for human well-being and economic development. The public has certain expectations regarding the functionality of the urban water infrastructure. European Standards [1] define the services that wastewater systems should provide for the community, for example removal of wastewater from premises for public health and hygienic reasons or prevention of flooding in urbanized areas and protection of the environment. Drinking water should be provided by the operating company in sufficient quality; quantity and pressure [2]. These are today's justified expectations of the community. Additionally, modern urban infrastructure faces major challenges while fulfilling these duties. Maintenance and rehabilitation of the existing aging networks are not only a financial but also an organizational challenge. Insufficient investments into the current systems may lead to a decrease of system performance and to a waste of resources. For water supply systems, this means for example an increase of water losses [3], for drainage systems an increase of sewer exfiltration and consequently an increase of environmental impact. Furthermore, the adaptation to a changing environment (e.g., climate change and/or urban development in the context of population increase/decrease) may require additional measures to maintain current service levels. The focus of operating companies in developed countries is therefore moving away from construction of new networks to maintenance, repair and 
adaptation, sometimes even reduction of the existing ones. This reduction has to be seen also in the context of decentralized systems e.g., for urban flood management [4].

State of-the-art projects in rehabilitation management for urban water networks [5-7] focus mainly on one single network alone while an integrated multi-utility approach is still seldom used $[8,9]$. Instead of examining all public networks separately, this paper presents an approach for a combined rehabilitation planning of different infrastructure networks. Thereby, the road network acts as a container for all networks and it is used for prioritization of rehabilitation measures. Thus, it is the aim of this study to identify those street sections that (and all their underlying networks) should be rehabilitated first.

However, the intertwined networks do not only differ in shape, length, construction depth, material, age, diameter and location but also in external influencing factors, which have to be considered (e.g., ground water level, climate, traffic, number of house connections, etc.). Additionally, there is also an interaction between networks. The interaction between the systems ranges from the disturbance of the functionality caused by the failure of an adjacent network (for example the closure of a road due to a water main break) or the damaging of the infrastructure due to the proximity of other networks (for example corrosion of steel pipes induced by stray currents of the tram system) to minor influences during the rehabilitation of adjacent networks (for example due to vibrations). On the other hand, synergies can and should be exploited in rehabilitation management. Costs, especially for excavation and surface re-construction, can be shared and therefore minimized if coordinated rehabilitation takes place.

Such interdependencies and the consideration of a variety of internal and external influencing factors make decision making very complex. The consideration of multiple networks also leads to the involvement of multiple stakeholder groups with different professional background, experience, expectations and financial constraints. Further, external political and societal influences add an additional level to this problem. To improve the communication between different stakeholder groups, it is advisable to objectify discussions by following a structured decision making procedure.

Because structures in urban water management have life expectancies of up to 100 years or even more, contemporary urban water systems are strongly influenced by historical decisions and implementations. In the same way, our decisions taken in rehabilitation planning for the urban water networks will have long lasting effects on the functionality and quality of future services provided by these networks.

While different multi-criteria-decision making (MCDM) methods with different complexity and assumptions exist, there is still a knowledge gap about the influence of the decision making method itself on the outcome. The aim of this paper is to compare different available MCDM methods for the application in an integrated rehabilitation management scheme $[9,10]$ and analyze them with respect to their suitability to be used in integrated asset management of water systems. As case study the water, drainage, gas and road network of a small municipality with 13,100 inhabitants is used. Consequently, it is analyzed if different MCDM methods lead to different prioritization in the rehabilitation of street sections with their underlying networks.

\section{Selection of Multi-Criteria Decision-Making (MCDM) Methods Based on Literature Review}

\subsection{Review of Available Methods}

MCDM methods cover a wide range of quite distinct approaches [11]. The last decades have intensified the interest in the application of formalized decision-analytical tools, due to the complexity of problems as well as the higher availability of data [12]. The available methods can be categorized into three schools [13-15]: 
- Value measurement models: A numerical score for each alternative is constructed. Furthermore, a weight $\mathrm{w}$ is assigned to each criterion, which represents the importance of the criterion (e.g., Weighted Sum Model, Analytic Hierarchy Process).

- Goal, aspiration and reference level models: These methods measure how good alternatives reach determined goals or aspirations (e.g., TOPSIS).

- Outranking models: These methods compare the alternatives pairwise for each criterion, finding the strength of preferring one over the other (e.g., ELECTRE, PROMETHEE).

The aim of this paper is to compare different multi-criteria decision making methods and investigate their applicability to integrated rehabilitation management of small and medium-sized municipalities. The idea is to compare simple methods with more complex methods. Hence, the three most used models in the field of water and wastewater infrastructure [16] are compared with the most basic method available - the weighted sum model. This method was chosen as a baseline scenario, due to its simplicity, straightforwardness and comprehensibility for the operators of water and wastewater infrastructure involved - especially in our small case study. In order to use a method from each of the three schools of MCDM methods [14], we used the TOPSIS method as a goal, aspiration and reference level model. It was chosen due to the fact, that although very few applications in the field of rehabilitation strategies for urban water infrastructure were available, TOPSIS is used regularly as an MCDM method [17] in a wide variety of fields, especially for strategy comparison in environmental sciences [12] and in the neighboring field of highway maintenance [18].

Because the methods are well known and explained in many publications $[13,15,19]$, here only a short overview and a short summary of the literature review is presented.

The most frequently used method (28.3\% of publications regarding water and wastewater [16]) is the Analytic Hierarchy Process (AHP) [20]. It is a widely used approach for obtaining preferences or weights of importance regarding to the criteria and alternatives for a variety of research fields. The advantages of this method are the possibility to use qualitative and quantitative criteria, the ordered fashion of the decision making which allows a good traceability of the decision and the quality assurance given by the consistency indices. Disadvantages are certainly the loss of information due to potential compensation effects between good scores on some criteria and bad scores on others [21] and the (depending on the number of criteria and alternatives) complex and time-consuming implementation [16]. In the past it was used in combination with an artificial neural network to evaluate the performance of water mains [22] and applied to urban flood management to determine the priority of flood vulnerable areas considering the technical, social and environmental aspects [23,24]. It was also part of an adjusted decision making support system for the rehabilitation planning of sewer systems [25] and used for estimation of weights in integrated rehabilitation management [9] as well as for the management of stormwater networks [26]. Furthermore, it is often used in combination with GIS for example for the landslide vulnerability of areas [27] or forest fire risks [28].

The next group of methods (with 15.1\% [16]) are the ELECTRE (ELimination Et Choix Traduisant la REalite) models. ELECTRE is a family of outranking methods consisting of seven different models (I, II, III, IV, A, IS and TRI) derived from the original ELECTRE I [29]. In addition, a hybrid method for fuzzy multiple criteria decision making (FELECTRE) exists [30]. An outranking relation is a preference model which takes into account three types of situations: preference, in-difference, and incomparability [31]. They are often used in Europe [16] in the wake of the CARE-W [5] and CARE-S [6] projects. It was used for the rehabilitation planning of sewers [32,33], as well as for urban stormwater drainage management $[34,35]$ and urban flood management [24]. For water distribution networks it was used to estimate performance indicators for small and medium sized water utilities [36], the amount and place of investments in water distribution networks [37] as well as for rehabilitation [38] and maintenance management [39]. ELECTRE I can be used for solving selection problems, ELECTRE TRI for assignment problems, and for ranking problems ELECTRE II-IV have been developed. The shortcomings of ELECTRE I are: (a) that it aims to select a smallest set of best alternatives, but not to construct an ordering of the alternatives from the best to the worst [31]; and (b) since the final results are 
sensitive to the vote threshold, it remains unknown how to determine the appropriate threshold [19]. The main difference between ELECTRE II and ELECTRE III is that ELECTRE III is non-compensatory and it incorporates the imprecise and uncertain (fuzzy) nature of the decision maker. Nevertheless, both methods are used for solving problems where the importance of the criteria can be quantified. For solving problems where this is not possible, ELECTRE IV is the best option [40]. For the case study presented in this paper, it is possible to quantify the relative importance of the criteria and since ELECTRE III also incorporates the fuzzy nature of the decision maker, ELECTRE III is used. Furthermore, it is the most commonly used variation of this method [16]. The main disadvantages are its expenditure in time, its complex application and the possible inability of the method to identify a preferred solution [41]. On the other hand, it can be applied even with missing information and under uncertainties [16] and even when there are incomparable alternatives [41]. Incomparability is an intrinsic feature of any evaluation matrix. Each alternative has good and bad performances on some criteria. Without additional information, no sound mathematical theory could decide which decision is the best. The final choice is left for the decision maker [42]. Another main advantage of ELECTRE III is that it is non-compensatory, which means a bad score on one particular criterion cannot be compensated by good scores on another criteria [40]. However, the method requests inter-criteria information that reflects the relative importance of the objectives established-the weight of each criterion [37].

The next group of methods (with 13.2\% [16]), the PROMETHEE (Preference Ranking Organization METHods for Enrichment Evaluations) methods, are another family of outranking methods, including PROMETHEE I, II, III, IV, V, and VI; GDSS; TRI; and CLUSTER [43]. The original PROMETHEE I $[44,45]$ is used to set up a partial preorder and PROMETHEE II to make a complete preorder. With PROMETHEE III an interval order can be made, and PROMETHEE IV is used when the set of permitted solutions is continuous [13,19]. The ranking of the alternatives with the methods of the PROMETHEE family is made by calculating a positive outranking flow and a negative outranking flow for each alternative. In PROMETHEE I and II, the indifferent case only occurs when the corresponding flows between two alternatives are equal. If the flows of two alternatives are very close to each other, the alternative with the higher flow is preferred. This can be avoided by using PROMETHEE III, in which an interval of indifference for each alternative is defined [19]. It reflects the decision behavior of the decision maker better than the other PROMETHEE methods. This is the reason why PROMETHEE III is used in this paper. The main advantage of this method is the fact that it allows for the direct operation on the variables included in the decision matrix, without requiring any normalization and is applicable even when there is information missing [41]. However, it can be time consuming and difficult to keep an overview over the problem when a lot of criteria are involved [16]. Furthermore, it is possible that the rank reversal problem occurs, which means that, in some cases, the ranking of the alternatives can be reversed when a new alternative is introduced [21]. However, it is seldom used in the field of rehabilitation management, but mainly in fields like environmental management, hydrology and water management, business and financial management, chemistry, logistics and transportation, manufacturing and assembly, energy management, social and other topics $[43,46]$.

Although the Weighted Sum Model (WSM) [47] is one of the simplest multi-criteria decision making methods, it is still quite often in use (3.8\% [16]). According to the WSM, the optimal alternative is the closest one to the "best" value. This value contains the maximum of all criteria. Weighted sum models are often used for single dimensional problems, as for example for only one network [48] with limited amount of data. However, they still provide similar results when compared with more sophisticated methods $[16,24,49]$. In rehabilitation management this is seldom the case due to the large amount of data and influences. It is mainly used, due to its simple application and because a more complicated approach would require a higher data quality. Sometimes it is applied together with other methods, for instance AHP [9], because of its simple applicability [49]. Applications can be found for the planning of urban infrastructures in general [50], the choosing of sewer rehabilitation methods [51] or urban flood management [24]. The weighted sum model is formulated for problems in which all 
variables have the same physical dimensions, being based on the "additive utility" assumption [52]. For multi-dimensional problems (e.g., qualitative and quantitative attributes), the problem becomes difficult to handle, as the aforementioned hypothesis is violated, and hence, normalization schemes must be employed [49]. Furthermore, compensation effects between the different criteria can be observed [41].

Finally, the last method chosen for this paper (with 1.9\% [16]) is the TOPSIS (Technique for Order Preference by Similarity to an Ideal Solution) method [53]. The main idea came from the concept of the compromise solution to choose the best alternative nearest to the positive ideal solution (optimal solution) and farthest from the negative ideal solution (inferior solution) [54]. Therefore, the chosen solution should have the shortest Euclidean distance from the ideal solution and the farthest Euclidean distance from the ideal negative solution. For the ideal positive solution, all the attribute values correspond to the maximal attribute values. For the ideal negative solution, all the attribute values correspond to the minimum available attribute values. However, both are hypothetical solutions [55]. The benefits are that the only judgments required are weights, while relative distances depend on the weights and on the range of alternatives themselves. The non-linear relationship between single dimension scores and distance ratios produces smoother trade-offs [12], considering both the positive and negative ideal solutions [41]. A weakness of the method is the need for vector normalization for multi-dimensional problems [16]. This method is mainly used for strategic decisions, energy and sustainable manufacturing problems [12]. However, it was also used in an adapted approach to design stormwater scenarios [34], for urban flood management [24] and the planning of urban infrastructures in general [50].

\subsection{Application of MCDM Techniques in Rehabilitation Planning}

Multi-criteria decision-making techniques in water infrastructure rehabilitation planning and asset management can be applied in all planning decision levels, ranging from the strategic down to the operational level [56]. They can be used for deciding on overall strategies and fund distribution over decades [37], for rehabilitation projects in near future [9,38] as well as for the decision about the immediate rehabilitation technique for an occurred failure [51]. Good decisions can best be reached when everyone included in the process has a clear view of how the process will work and also has acknowledged this procedure. At the end, everybody involved should be confident of his/her decisions [14]. Multi-criteria decision-making (MCDM) provides this systematic approach in combining different inputs with benefit/cost information and decision-maker or stakeholder views to rank the alternatives [16]. Such a decision-making process provides the following advantages [57]:

- Structure for approaching current and future complex problems;

- A rational view on the problems and rational ranking of the possible solutions;

- Consistency and objectivity in the decision making process;

- Documentation of all the assumptions used, criteria, and values used to make decisions for later review and for usage for future problems; and

- Every decision is repeatable, reviewable, revisable and easy to understand.

Multi-criteria decision-making models used for planning infrastructure management are limited to give suggestions for infrastructure managers about where and when rehabilitation works can be executed. Decision-making in reality, however, is based on a relatively large set of interrelated decision criteria, where the importance of each criterion varies per replacement project, depending on unique local circumstances and personal preferences of an asset manager [58]. The actual operational decisions for when, with whom, where and how works are executed are taken by a variety of stakeholders. Therefore, setting up the priority model by the various stakeholders involved in cooperation creates a shared understanding of each other's reasoning. The discussion should however lead to at least the recording of decisions and their reasons by the operating company to evaluate existing plans and enhance future planning processes. Finally, factors which derive from the operator's experience, such 
as problems with the quality of workmanship in certain areas or similar points cannot be grasped by statistical means, the so called intuition $[58,59]$ (or experience) should be considered as well. These motivations and motives as well as the importance of experience can then be expressed in weighting and thresholds.

\section{Materials and Methods}

In this work, three different networks, sewer, water and gas as well as the road are considered. For each network, every method was applied individually. Finally, a complete ranking is made, again using the five methods. Below, firstly, the results of the five different methods are shown individually and the results of the methods will be compared with each other, finding similarities and deviations. Because the AHP is the most widely applied method, it is used as reference for the comparison. The results are compared for each network individually as well as for the integrated consideration of all networks. A sensitivity analysis is carried out, due to the fact that the rankings depend greatly but not solely on the chosen and calculated weights of each criterion.

To compare the different multi-criteria decision support methods and to examine their applicability, a case study of a small municipality with 13,100 inhabitants is used [10]. The available data contains the water supply and gas distribution networks and their failure history as well as the data of the sewer and its condition. Due to the inconsistency and scarcity of the available data, a semi-automatic data reconstruction methodology [60] was applied to obtain a complete dataset. Since, water supply, sewer and gas distribution network and condition/failure data were available, an integrated, multi-utility approach is enabled [10]. Therefore, an existing methodology [9] was adapted to a small case study and limited data quality [10].

\subsection{Definition of Criteria and Weights in Integrated Rehabilitation Management}

The pipe networks are divided into pipe sections. Pipe sections are defined as a homogeneous part of the street section with constant parameters like material, diameter and construction year [61]. A street section consists of several pipe sections. To ensure applicability and comparability of the different street sections, the chosen street sections do not exceed a certain length [9].

For each network influencing factors or criteria are assigned which represent different element of the rehabilitation decision (e.g., condition of the pipe section). To evaluate the characteristics within the criteria, score scales between 0 and 100 are used, where 0 means no influence and 100 means significant influence [10].

For every pipe, these scores are assigned to every criterion. The definition of these scores is explained in the following sections. Afterwards, the calculated individual scores are added proportional to the pipe lengths to a total score for each criterion. Together with the scores of the criteria on the street level, these scores are weighted to a final representative value for each street section (see Figure 1).

For rehabilitation management, a prioritization of street sections containing all available infrastructure was applied using the priority of each individual network and street condition data to estimate an overall priority of the areas for an integrated rehabilitation management. 


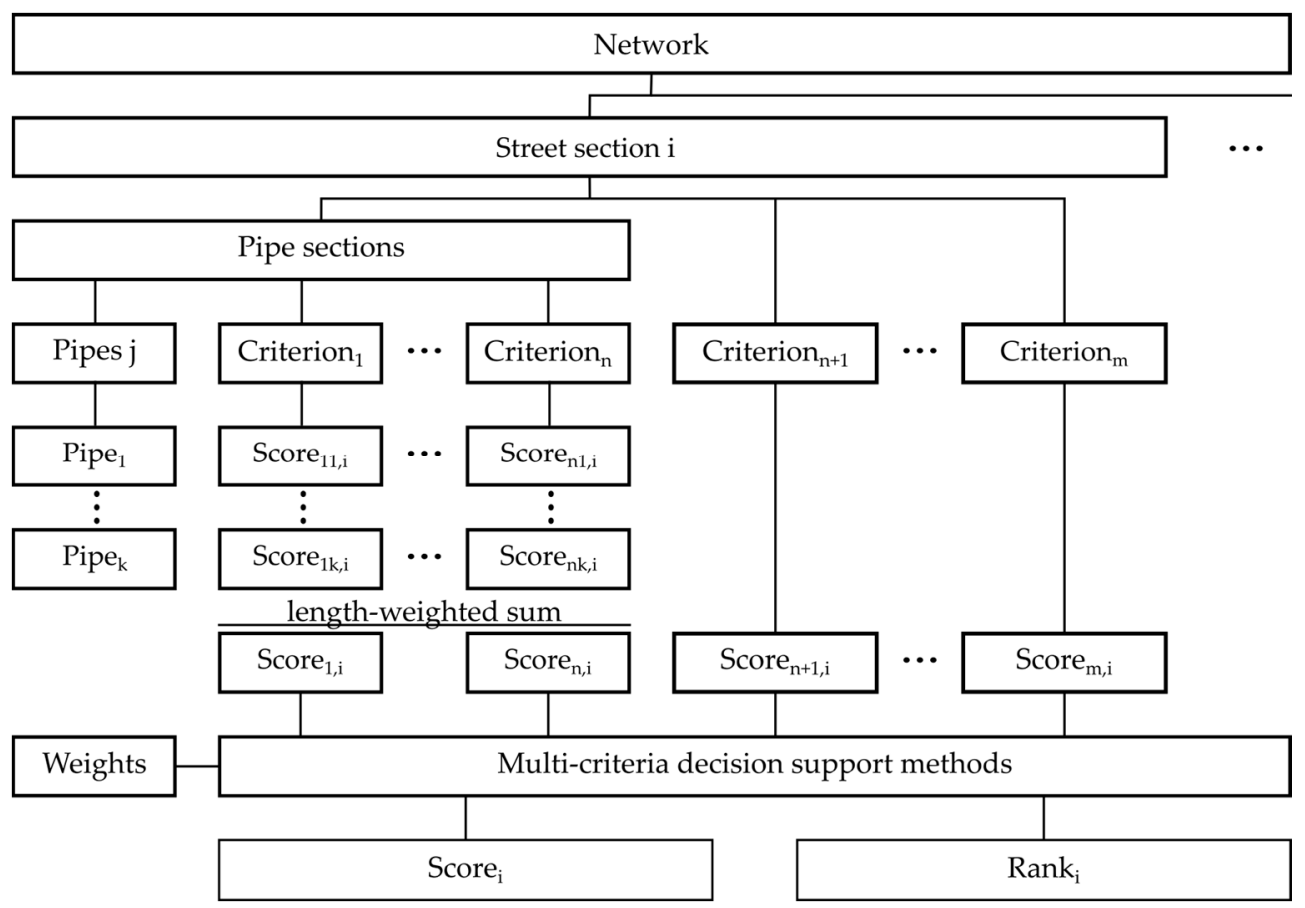

Figure 1. Flowchart of the score and rank estimation for the individual networks.

\subsubsection{Sewer Network}

The sewer network is considered separately on pipe level and street level. On the pipe level, three main categories with 1-3 criteria and their characteristics are taken into account. On the street level, two extra criteria are considered (see Table 1). These three main categories derive from the available data and the classical key figures for infrastructure asset management of urban water systems: risk, performance and costs [56]. Risk bases on the probability and the consequence of failure. These two factors are represented by the condition of the pipe and the importance for the network which would lead to higher consequences for the failure of more important pipes. This importance includes also the performance of the pipe section (e.g., the hydraulic capacity for sewers). Costs are represented by the economic value of the pipe section. e.g., if it is fully depreciated or not.

Table 1. Influencing factors for the sewer network.

\begin{tabular}{|c|c|c|c|c|c|c|c|}
\hline \multicolumn{6}{|c|}{ Pipe Level } & \multirow{2}{*}{\multicolumn{2}{|c|}{ Street Level }} \\
\hline & ondition & & & Importance & & & \\
\hline Material $^{1}$ & $\begin{array}{l}\text { Diameter } \\
\text { DN (m) }\end{array}$ & $\begin{array}{c}\text { Age } \\
\text { (Years) }\end{array}$ & $\begin{array}{c}\text { Hydraulic } \\
\text { Capacity (\%) }\end{array}$ & Pipe Type $^{2}$ & Economics & $\begin{array}{c}\text { House } \\
\text { Connections }\end{array}$ & Manholes \\
\hline $\begin{array}{c}\text { AC } \\
\text { C } \\
\text { DI } \\
\text { PVC } \\
\text { VC } \\
\text { RC }\end{array}$ & $250-1600$ & $0-60$ & $\begin{array}{c}\leq 50 \\
50-100 \\
100-150 \\
150-200 \\
>200 \\
\text { No data }\end{array}$ & $\begin{array}{l}\text { WW } \\
\text { CS } \\
\text { SW }\end{array}$ & $\begin{array}{c}\text { Depreciation } \\
\text { derived } \\
\text { from age }\end{array}$ & $\begin{array}{l}\text { Number of } \\
\text { house } \\
\text { connections } \\
\text { per m sewer }\end{array}$ & $\begin{array}{c}\text { Number of } \\
\text { manholes } \\
\text { per m } \\
\text { sewer }\end{array}$ \\
\hline
\end{tabular}

Notes: ${ }^{1}$ Asbestos cement (AC), Concrete (C), Ductile iron (DI), Polyvinylchloride (PVC), Vitrified clay (VC), Reinforced concrete (RC); ${ }^{2}$ Wastewater (WW), Combined sewage (CS), Stormwater (SW).

For the condition driven criteria the length of sewers in poor condition, using DWA classification [62], was used to estimate the score for the different influences [10]. For instance, the score of the material with the highest percentage of pipes (referred to their length) in condition classes 0 and 1 is set to 100 (see Figure 2). The scores of the other materials are set according to their 
percentages. This distinction in condition classes is more differentiated, than the binary classification into unacceptable and acceptable condition, used for some deterioration models $[63,64]$. Pipes in condition class 0 (immediate action necessary) were set to have a larger impact on the result than others. The pipes in condition class 0 were assumed to have double the impact than pipes in condition class 1 (short term action necessary). When comparing the different materials (Figure 2), it can be observed that the concrete (C) pipes are in the worst condition. In contrast, there are no pipes of asbestos cement (AC) or ductile iron (DI) in the condition classes 0 or 1.
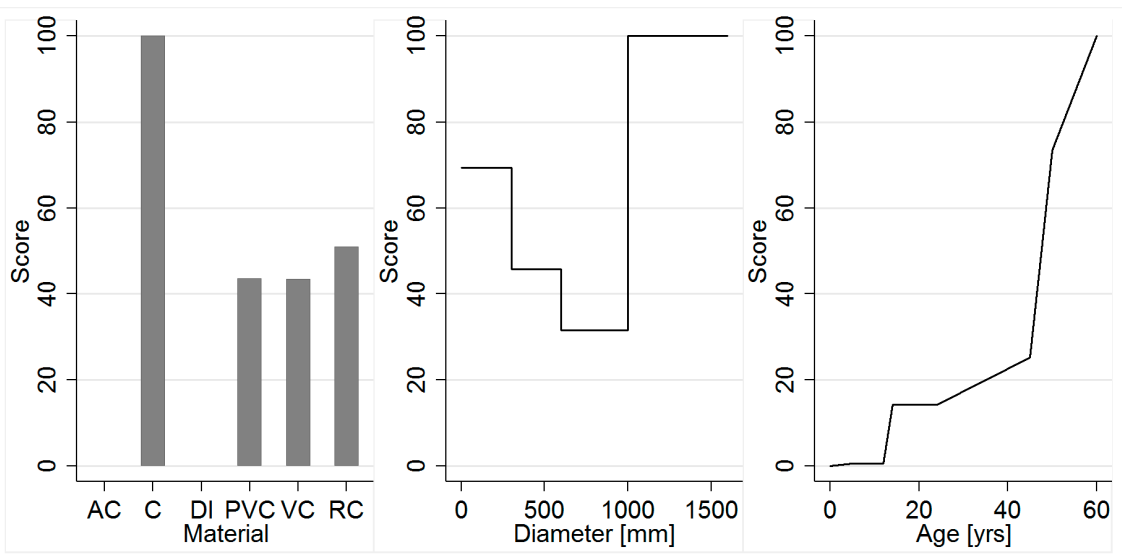

Figure 2. Scores of the condition driven criteria for the sewer network.

For the criterion "diameter", the same assumptions as for the criterion "material" are made. To create a score scale for the pipe condition according to the diameter, the different diameters of the sewer network are classified into four different classes, depending on the condition data. In this case, diameters higher than $1000 \mathrm{~mm}$ are in the worst condition because the percentage of pipes with a diameter larger than $1000 \mathrm{~m}$ in condition class 0 and 1 is higher than for any other diameter class. However, the pipes with small diameters $(\leq \mathrm{DN} 300)$ are in bad condition. Pipes with a diameter between 600 and $1000 \mathrm{~mm}$ are in good condition-relative to the rest of the sewer network.

To create a score scale which represents the condition of the pipe sections according to their age, the cumulative sum of pipe lengths in condition class 0 and 1 is used. It increases over the pipe age. Due to limited data quality for the sewer system, the score scale consists of few kinks. However, it clearly shows that especially pipes which are older than 50 years are in bad conditions.

The aim of the "importance" category of influencing factors is to obtain a prioritization of the pipes according to the importance for the operator. Hydraulic utilization is defined as the proportion of the estimated maximum flow in relation to the pipe capacity for full pipe flow. When the estimated maximum flow exceeds the pipe capacity pressurized flow or flooding occurs [65]. For the estimation of the maximum flow a hydrodynamic simulation of the urban drainage system using a design rainfall [66] event for a specific return period between 1 and 10 years (depending on the land use) is applied. However, this data is unknown for some newer parts of the network. In these cases, the hydraulic capacity is assumed as sufficient because they have been constructed and designed recently. The scores are assigned using an evaluation scheme based on an existing hydraulic rehabilitation prioritization matrix [67] including the type of drainage system, the kind of pipe and the hydraulic utilization. Since the kind of pipe (main or secondary pipe) is not known from the available data, pipes with a diameter higher than $1000 \mathrm{~mm}$ are assumed as main pipes, and the rest as secondary pipes. The highest priority is given to the main wastewater and combined-sewer pipes that exceed their hydraulic capacity with a maximum score of 100 . Sub-main wastewater and combined-sewer pipes which exceed their hydraulic capacity get scores proportional to their diameter, in an individual score range of 60 and 100. To main stormwater pipes with a hydraulic capacity $>100 \%$, a score of 80 is assigned. Hence, wastewater pipes with DN500 are equally important as stormwater pipes with DN 
$>1000$ if both exceed their hydraulic capacity. For sub-main stormwater pipes, the scores are between 40 and 80, depending on their diameter. Finally, individual scores are assigned to pipes which do not exceed their hydraulic capacity. With the assumption that larger pipes have also a higher importance for the operator because they have an impact on a larger area, individual scores between 0 and 40 are set to these pipe sections.

Because around $80 \%$ of the observed sewer network is located in the ground water, the type of sewer is also a factor for itself in terms of importance to the environment.

Pipe leakages can cause large environmental impacts. The most relevant impacts are generated by the wastewater pipes (WW), followed by the combined sewer (CS). The impact of leakage of pure stormwater pipes (SW) is negligible. Hence, the maximum score of 100 is assigned to the WW pipes, 80 to the combined sewers and no individual scores are given to SW pipes in this criterion.

The economic factor considers the depreciation of the pipes. The technical lifetime of the sewer is considered between 50 and 80 years according to the German guidelines [68]. For the operator, replacing a pipe before it reaches its technical lifetime is not economically viable. Hence, no individual scores are given to pipes until they reach 50 years. On the other hand, pipe replacement after reaching the limit of 80 years becomes economical, and therefore a full score of 100 is given to these pipes. Between these two limits, a linear relation is assumed.

On the street level, it is assumed that in case of damage the street section with the highest number of house connections per running meter has the highest impact on the residential area. The maximum individual score of 100 is assigned to this street. The other street sections get individual scores $\mathrm{s}$ in relation to their number of house connections per running meter. The same considerations are taken for the manholes.

\subsubsection{Water Distribution Network}

The structure for the water distribution network is similar to the sewer. The first step was again to estimate the influence factors (see Table 2). The pipe level is split up in three main categories with respectively 1-3 criteria and their attributes. On the street level, three criteria are considered.

Table 2. Influencing factors for the water distribution network.

\begin{tabular}{|c|c|c|c|c|c|c|c|c|}
\hline \multicolumn{6}{|c|}{ Pipe Level } & \multirow{2}{*}{\multicolumn{3}{|c|}{ Street Level }} \\
\hline & ondition & & Importa1 & & & & & \\
\hline Material $^{1}$ & $\begin{array}{l}\text { Diameter } \\
\text { DN (mm) }\end{array}$ & $\begin{array}{l}\text { Age } \\
\text { (Years) }\end{array}$ & $\begin{array}{c}\text { Nominal } \\
\text { Pressure (Bar) }\end{array}$ & $\begin{array}{c}\text { Pipe } \\
\text { Type }{ }^{2}\end{array}$ & Economics & $\begin{array}{c}\text { House } \\
\text { Connections }\end{array}$ & Valves & Hydrant \\
\hline $\begin{array}{c}\text { CI } \\
\text { DI } \\
\text { PE } \\
\text { PVC } \\
\text { ST }\end{array}$ & $20-300$ & 0-92 & $\begin{array}{c}6 \\
10 \\
16\end{array}$ & $\begin{array}{l}\mathrm{HC} \\
\mathrm{DP}\end{array}$ & $\begin{array}{c}\text { Depreciation } \\
\text { derived from } \\
\text { age }\end{array}$ & $\begin{array}{c}\text { Number of } \\
\text { house } \\
\text { connections } \\
\text { per m } \\
\text { distribution pipe }\end{array}$ & $\begin{array}{l}\text { Number of } \\
\text { valves per m } \\
\text { distribution } \\
\text { pipe }\end{array}$ & $\begin{array}{l}\text { Number of } \\
\text { hydrants } \\
\text { per } m \\
\text { distribution } \\
\text { pipe }\end{array}$ \\
\hline
\end{tabular}

Notes: ${ }^{1}$ Cast Iron (CI), Ductile Iron (DI), Polyethylene (PE), Polyvinylchloride (PVC), Steel (ST); ${ }^{2}$ House connections (HC), Distribution pipes (DP).

For the water distribution network, the failure data over the last 10 years is available. The number of occurring failures is used as a factor to describe the condition criteria of the water pipes, similar to the usage of condition states for the sewer to estimate the scores defined by condition (see Figure 3).

It can be seen that most of the failures occur in cast iron (CI) and steel (ST) pipes, which are nowadays not used anymore in the water network. Contrarily, barely failures occur in newer ductile iron (DI) pipes. Furthermore, in smaller pipes more failures are observed. On pipes with a diameter larger than $200 \mathrm{~mm}$, no failures occurred over the last 10 years. Figure 3 shows that the number of failures are linear until a pipe age of 25 years. Afterwards, a rapid increase of failures can be observed. 

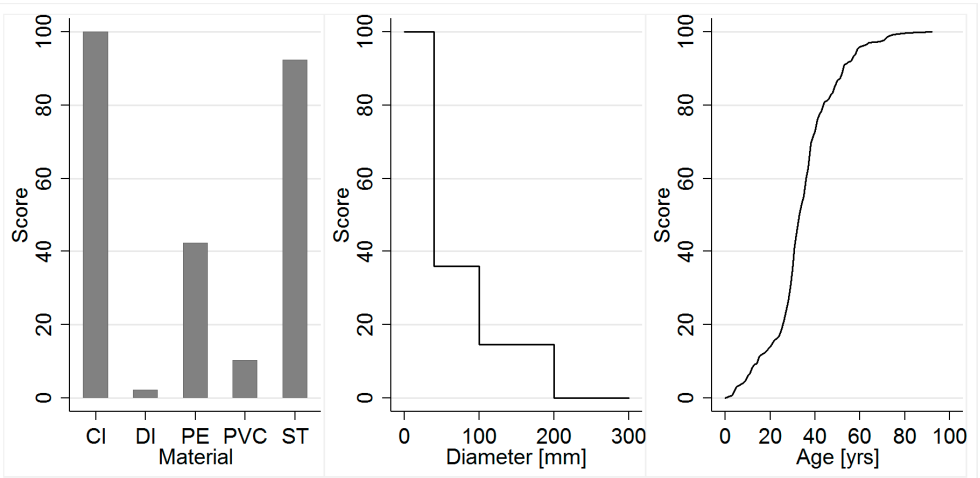

Figure 3. Scores of the condition driven criteria for the water distribution network.

The category "importance" aims to obtain a prioritization of the pipes according to the importance for the operator. A prioritization of the existing water network is developed according to the nominal pressure and diameter. Since the majority of the pipes ( $99 \%$ ) have the same nominal pressure, a prioritization depending solely on the pressure makes no sense. Bearing in mind that higher diameters influence a larger area and more population in case of damage, pipes with a larger diameter have a higher score. Hence, the maximum score of 100 is assigned to pipes with a higher diameter than 200, and a score which is proportional to the diameter of the pipes corresponds to smaller pipes. In addition, damage to a house connection has a much smaller impact than damage to a main pipe. Hence, the scores for the house connections are set to 0 , whereas the scores for the main pipes are set to the maximum value of 100 .

The "economics" factor considers the depreciation of the pipes in the same way as for the sewers. Only the technical lifetime differs and is considered between 40 and 60 years according to the German guidelines [68]. The influencing factors on the street level is estimated the same way as for the sewers, considering house connections, valves and hydrants.

\subsubsection{Gas Distribution Network}

The structure for the gas distribution network is similar to the sewer and water distribution network. The first step was again to estimate the influence factors (see Table 3). The pipe level is split up in three main categories with 1-3 criteria respectively- and their attributes. On the street level, two criteria are considered.

Table 3. Influencing factors for the gas distribution network.

\begin{tabular}{|c|c|c|c|c|c|c|c|}
\hline \multicolumn{6}{|c|}{ Pipe Level } & \multirow{2}{*}{\multicolumn{2}{|c|}{ Street Level }} \\
\hline \multicolumn{3}{|c|}{ Condition } & \multicolumn{3}{|c|}{ Importance } & & \\
\hline Material $^{1}$ & $\begin{array}{l}\text { Diameter } \\
\text { DN (mm) }\end{array}$ & $\begin{array}{l}\text { Age } \\
\text { (Years) }\end{array}$ & $\begin{array}{l}\text { Nominal } \\
\text { Pressure }\end{array}$ & Pipe Type $^{2}$ & Economics & $\begin{array}{c}\text { House } \\
\text { Connections }\end{array}$ & Valves \\
\hline $\begin{array}{l}\text { PE } \\
\text { ST }\end{array}$ & $20-250$ & $0-50$ & $\begin{array}{l}\text { High, } \\
\text { low, } \\
\text { medium }\end{array}$ & $\begin{array}{l}\mathrm{HC} \\
\mathrm{DP}\end{array}$ & $\begin{array}{l}\text { Depreciation } \\
\text { derived } \\
\text { from Age }\end{array}$ & $\begin{array}{l}\text { Number of house } \\
\text { connections per m } \\
\text { sewer }\end{array}$ & $\begin{array}{c}\text { Number of valves } \\
\text { per m distribution } \\
\text { pipe }\end{array}$ \\
\hline
\end{tabular}

As for the water network, the failures are reported over the last 10 years and the number of failures is used to describe the condition of the gas pipes. The same assumptions as for the water distribution network are made and result in the scores for the condition driven criteria (see Figure 4). It can be seen that the majority of the failures occur in steel (ST) pipes, as it happened in the water network. Fewer failures occur in the newer polyethylene (PE) pipes. Medium-sized pipes are the most error-prone. In pipes with a diameter larger than $175 \mathrm{~mm}$, no failures occurred over the last 
10 years. Similar as for the sewer network, the cumulative sum of reported failures is used in order to create a score scale which represents the condition of the pipe sections according to their age. It can be noted that the gas network in this municipality is relatively young compared to the other networks. The maximum age of the pipes in this network is 50 years.
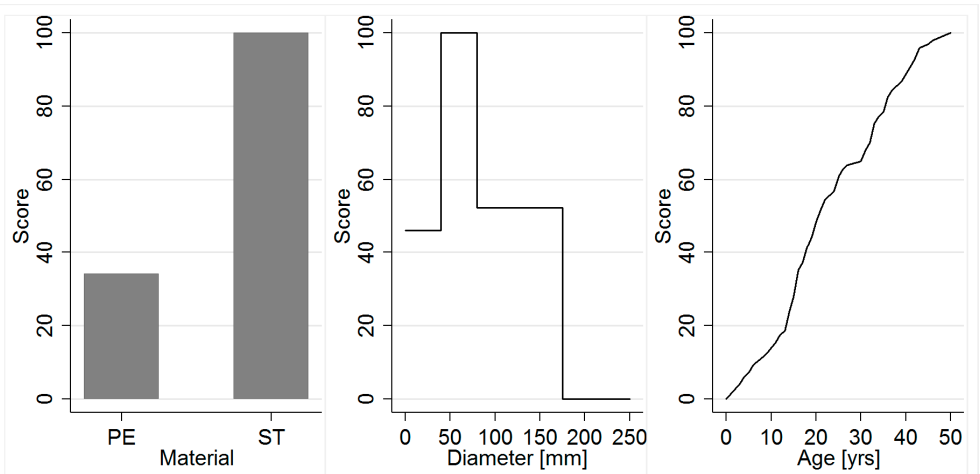

Figure 4. Scores of the condition driven criteria for the gas distribution network.

The aim of the "importance" category of influencing factors is to obtain a prioritization of the pipes according to the importance for the operator. For the importance, a prioritization using the pressure and diameter is used, taking into account that damages to the high pressure pipes and/or higher diameters affect more people and larger areas. The highest scores are assigned to pipes with a high pressure (60-100, depending on the diameter). Gas pipes with medium pressures get individual scores between 40 and 80 . Here, it is assumed that smaller pipes (DN100) with high pressures are as important as medium pressure pipes with $\mathrm{DN}>200$. The lowest score, which is ranged between 0 and 40 , is assigned to low pressure pipes which have the lowest importance in the network. The other influencing factors regarding the type of pipe, economics and the street level influences are estimated the same way as for the sewer and water distribution network.

\subsection{Weights and Indices}

To calculate the performance weights $\mathrm{w}_{\mathrm{j}}$, different weights (called $\mathrm{w}_{\mathrm{k}}, \mathrm{w}_{\mathrm{l}}$ and $\mathrm{w}_{\mathrm{m}}$ ) are defined as follows:

- $\quad \mathrm{w}_{\mathrm{k}}$ considers the different influence of pipe and street level criteria.

- $\mathrm{w}_{1}$ weights the three criteria on the pipe level. In our case study, this is the weighting of "condition" vs. "importance" vs. "economics".

- $\mathrm{w}_{\mathrm{m}}$ represents the weighting of the influencing factor within the main categories. In our case study, for example the weighting of "material" vs. "diameter" vs. "age" for the "condition" criteria.

- Finally, $\mathrm{w}_{\mathrm{j}}$ is the product of these three weights.

To define the weights for the WSM, the decision maker compares the different criteria pairwise by using a rating schema. This approach guarantees a transparent and comprehensible definition of the weights [51]. For the weights in the WSM and for the AHP six experts have been consulted. All six compared the criteria pairwise using one time a simplified rating schema for WSM [51] and the typical Saaty scale [20] on another occasion for plausibility checking. Since two experts were inconsistent in those terms when making these two ratings (reverse on the preference orders), only the average values of the other experts are used for the calculations. Furthermore, the consistency index and consistency ratio [20] was calculated for the AHP scale and found consistent. A comparison of the weights of the consistent experts and all experts shows that the ranges of the defined weights are much higher using the weights of all the experts (see as an example Table 4). The differences for the AHP method are even larger than for the WSM method, except for "economics". The weights which represent the 
criteria "condition" and "importance" show a range of nearly 0.50 . This means that one expert assigns three times more weights than the lowest weight given by another expert. Looking at the results of the consistent experts, the values are in an acceptable range. The consistent weights are therefore used for WSM and AHP.

Table 4. Comparison of the weights $\mathrm{w}_{1}$ of all and the consistent experts for the sewer network for WSM and AHP.

\begin{tabular}{|c|c|c|c|c|c|c|c|c|c|c|c|}
\hline & \multirow{2}{*}{$\mathbf{w}_{1}$} & \multicolumn{5}{|c|}{ All Experts } & \multicolumn{5}{|c|}{ Consistent Experts } \\
\hline & & $\bar{w}^{1}$ & $\sigma^{2}$ & Min & $\operatorname{Max}$ & Range & $\bar{w}^{1}$ & $\sigma^{2}$ & Min & Max & Range \\
\hline \multirow{3}{*}{ WSM } & Condition & 0.44 & 0.08 & 0.28 & 0.50 & 0.22 & 0.50 & - & 0.50 & 0.50 & - \\
\hline & Importance & 0.34 & 0.05 & 0.28 & 0.44 & 0.17 & 0.32 & 0.02 & 0.28 & 0.33 & 0.06 \\
\hline & Economics & 0.21 & 0.05 & 0.17 & 0.28 & 0.11 & 0.18 & 0.02 & 0.17 & 0.22 & 0.06 \\
\hline \multirow{3}{*}{ AHP } & Condition & 0.59 & 0.18 & 0.24 & 0.73 & 0.49 & 0.70 & 0.04 & 0.64 & 0.73 & 0.09 \\
\hline & Importance & 0.32 & 0.17 & 0.19 & 0.67 & 0.48 & 0.21 & 0.03 & 0.19 & 0.26 & 0.07 \\
\hline & Economics & 0.09 & 0.02 & 0.07 & 0.11 & 0.05 & 0.08 & 0.01 & 0.07 & 0.10 & 0.04 \\
\hline
\end{tabular}

Finally, a complete ranking for all the three networks (sewer, water and gas) as well as the road work is made. Since not all of these networks are equally important for the operator, the different networks are weighted. The definition of this weight is made by consulting again six experts. The resulting weights using again the mean value of the consistent experts only derives in weights of 0.11 for the sewers, 0.31 for the water distribution network, 0.45 for the gas distribution network and 0.13 for the roads.

Additionally, to the weights, the specific parameters of the ELECTRE methods, the indifference $\left(q_{j}\right)$, preference $\left(p_{j}\right)$ and veto $\left(v_{j}\right)$ thresholds need to be defined. The values for the indifference and preference thresholds are set according to the sensitivity of the criteria and distribution of the scores. For the majority of the criteria, the use of the powerful veto threshold $v_{j}$ does not make sense. Thus, normally no value is set. Only the veto threshold of the criterion "economics" is set to a value of 50. Hence, the older pipes that exceed their technical lifetime cannot be outranked by newer pipes if the score difference in the criterion "economics" is at least 50. The aim of this threshold is to make sure that also smaller and more insignificant pipes of the whole system which already reached the end of their technical lifetime are ranked for replacement. Due to the fact, that the score schemes in this case study were made on the pipe level, and that they were summed up according to the pipe lengths and the street section, the direct reference to the scores is lost. Consequently, the definition of the threshold values of this case study is not that simple. In the case of the "economics" veto threshold a sensitivity analysis was carried out and the results of different veto thresholds compared and checked for plausibility. Using the ELECTRE III method, it could happen that two or more street sections are indifferent and have an equivalent ranking position. To enhance comparability between the different methods, a ranking between these street sections is done manually. This manual ranking was performed only between two equally ranked street section and preferred section with longer pipe networks, considering that a longer pipe impacts on a larger area. Practically, taking into account other important aspects could be useful in these cases.

As for the ELECTRE method, the AHP weights are used for the PROMETHEE III and the TOPSIS method. Furthermore, for PROMETHEE, the shapes of the preference functions also need to be defined. In this case study, the shape of Type V: Linear criterion has been chosen for all criteria. Using this shape, in the case of a small score difference between two alternatives, none of these alternatives is preferred. Additionally, there exists also a zone of weak preference. This describes the real choice behavior of the decision makers and it is consistent with the ideas of ELECTRE III and enhances therefore comparability. The two needed parameters $\mathrm{p}$ and $\mathrm{q}$ are defined according to the same considerations as the ones made for the ELECTRE method. All these parameters are needed to calculate the preference 
index $\mathrm{P}(\mathrm{a}, \mathrm{b})$. Moreover, PROMETHEE III associates an interval $\left[\mathrm{x}_{\mathrm{a}} ; \mathrm{y}_{\mathrm{a}}\right]$ to each criterion. Hence, the parameter $\alpha$ is needed, which is set to $\alpha=0.10$.

Since the weights defined by the six experts have shown large deviations, it is obvious that these definitions are still subjective and contain uncertainties. Thus, it is important to understand the impact of changing these weights on the calculated ranking.

\section{Results and Discussion}

Figure 5 shows the results of ranking estimated by the reference method AHP for each network individually (Figure $5 \mathrm{a}-\mathrm{c}$ ) and for the integrated prioritization (Figure $5 \mathrm{~d}$ ).

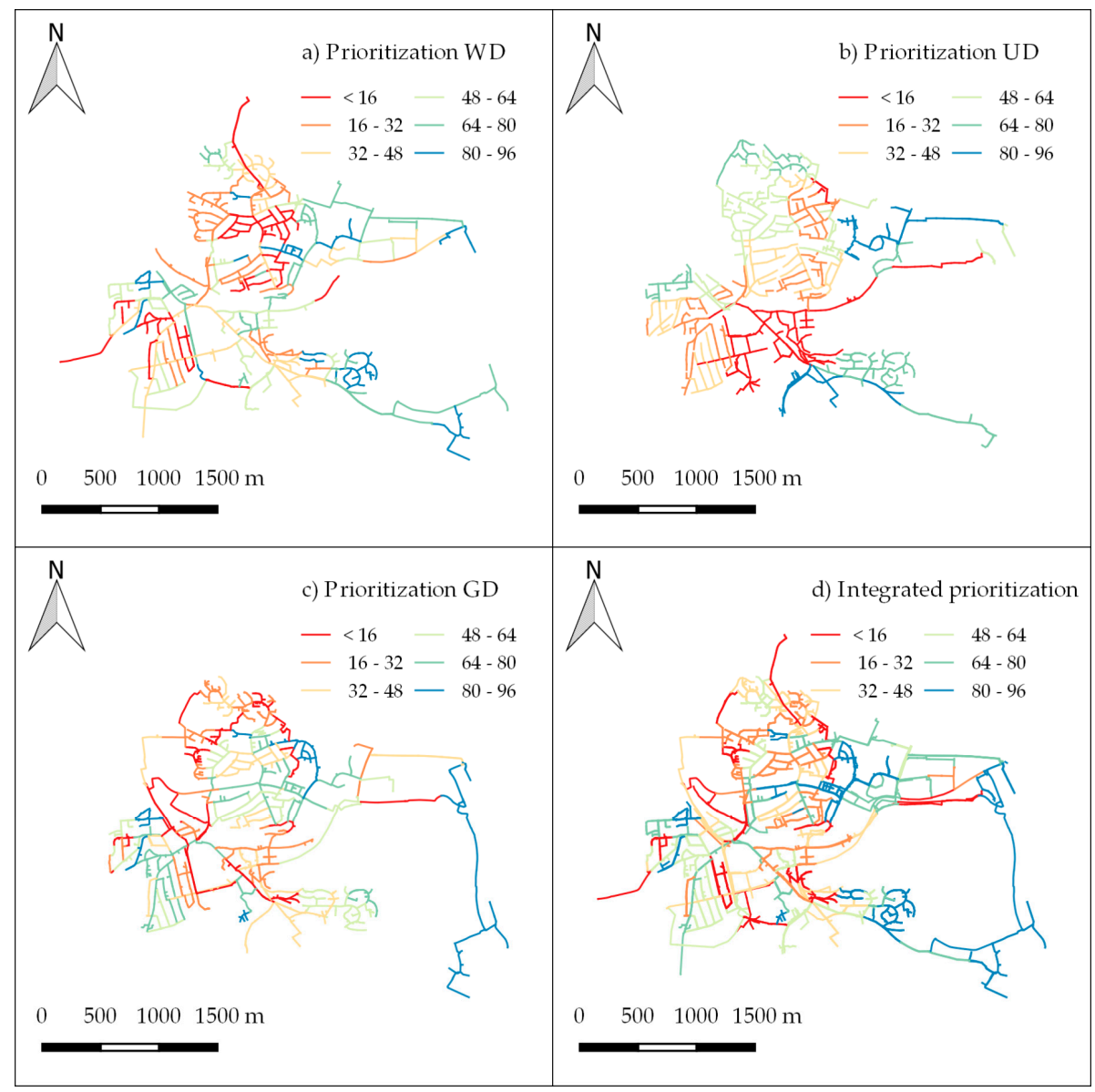

Figure 5. Result of the prioritization using the AHP method for: (a) the water distribution (WD) network; (b) the urban drainage (UD) network; (c) the gas distribution (GD) network; and (d) the integrated prioritization including the three networks and the road condition.

\subsection{Sewer}

Figure $5 \mathrm{~b}$ displays the preference ranking according to the AHP method for the sewer network. It is visible that the main interest for this network is situated in the central-south area, as well as in the central-north area of the system. Figure 6a shows the 10 highest ranking positions of the 96 street sections (abbreviated as letters) obtained with the AHP method in comparison with the ranking of the other four methods. As it can be seen, the first three ranks are equal with the WSM, AHP and TOPSIS methods. The following street sections are ranked higher using the TOPSIS method. Regarding the two outranking methods, their first and second ranks differ from the AHP ranking. Afterwards, the ELECTRE ranking fits well with the AHP ranking. In general, it can be said that the results are similar. If we look at the standard deviation of the absolute differences between the different methods 
(see Table 5), we can see that they range between 2 and 8 ranks. It can be seen, that while the other methods have a quite good accordance with the results of the AHP (see also Figure 6b), the ELECTRE results deviate slightly more from the rest (see Figure 7). They are attributable to the occurring ranking reverse when making the descending and ascending distillations in ELECTRE. Furthermore, the ranking variations are amplified by the differences between the AHP and the outranking methods.
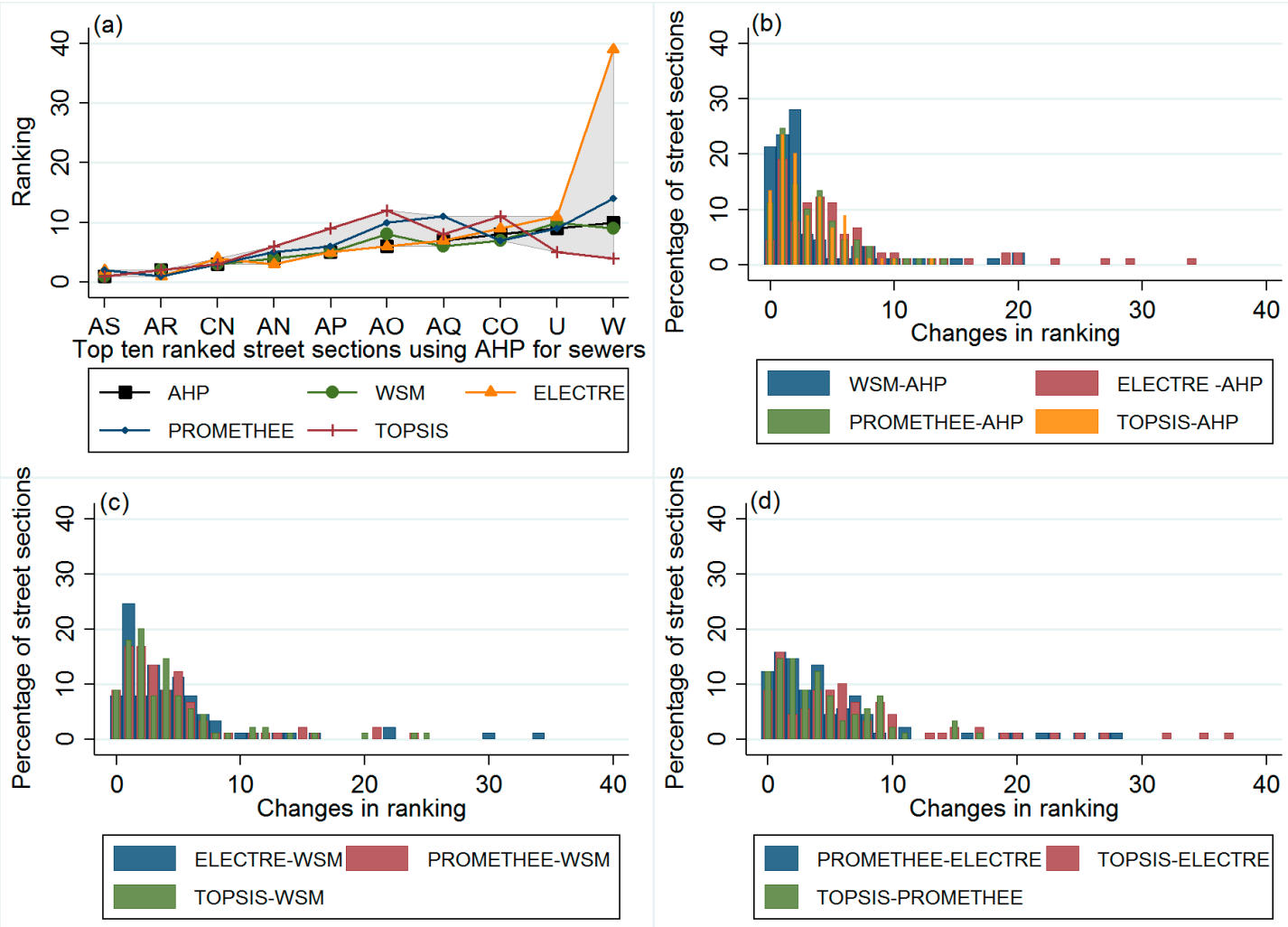

Figure 6. Comparison of the rankings of the sewer system using the different methods: (a) for the 10 top ranked street sections; (b) the absolute ranking differences with the AHP; (c) the absolute ranking differences with the WSM; and (d) the absolute ranking differences with ELECTRE and PROMETHEE.

Table 5. Standard deviation $\sigma$ of the sewer ranking between the different used methods.

\begin{tabular}{|c|c|c|c|c|c|}
\hline$\sigma$ & AHP & WSM & ELECTRE & PROMETHEE & TOPSIS \\
\hline AHP & - & 2.94 & 6.00 & 3.30 & 2.81 \\
\hline WSM & & 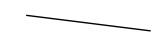 & 4.72 & 4.38 & 4.27 \\
\hline ELECTRE & & & 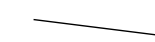 & 5.10 & 7.10 \\
\hline PROMETHEE & & symmetric & & 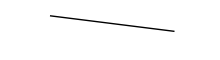 & 4.31 \\
\hline
\end{tabular}

In Figure $6 \mathrm{~b}$, the ranking differences between the WSM and AHP methods are displayed. It can be seen that the largest part ( $81 \%$ ) of the sewer network has a negligible ranking difference between 0 and 2 ranks. Generally, the ranking differences can be attributed to the different weights, since the two methods use the same equations. Particularly, the criteria "age" and "material", which get weighted with 0.21 using the WSM method and 0.30 using the AHP method, have a large influence on the result. 


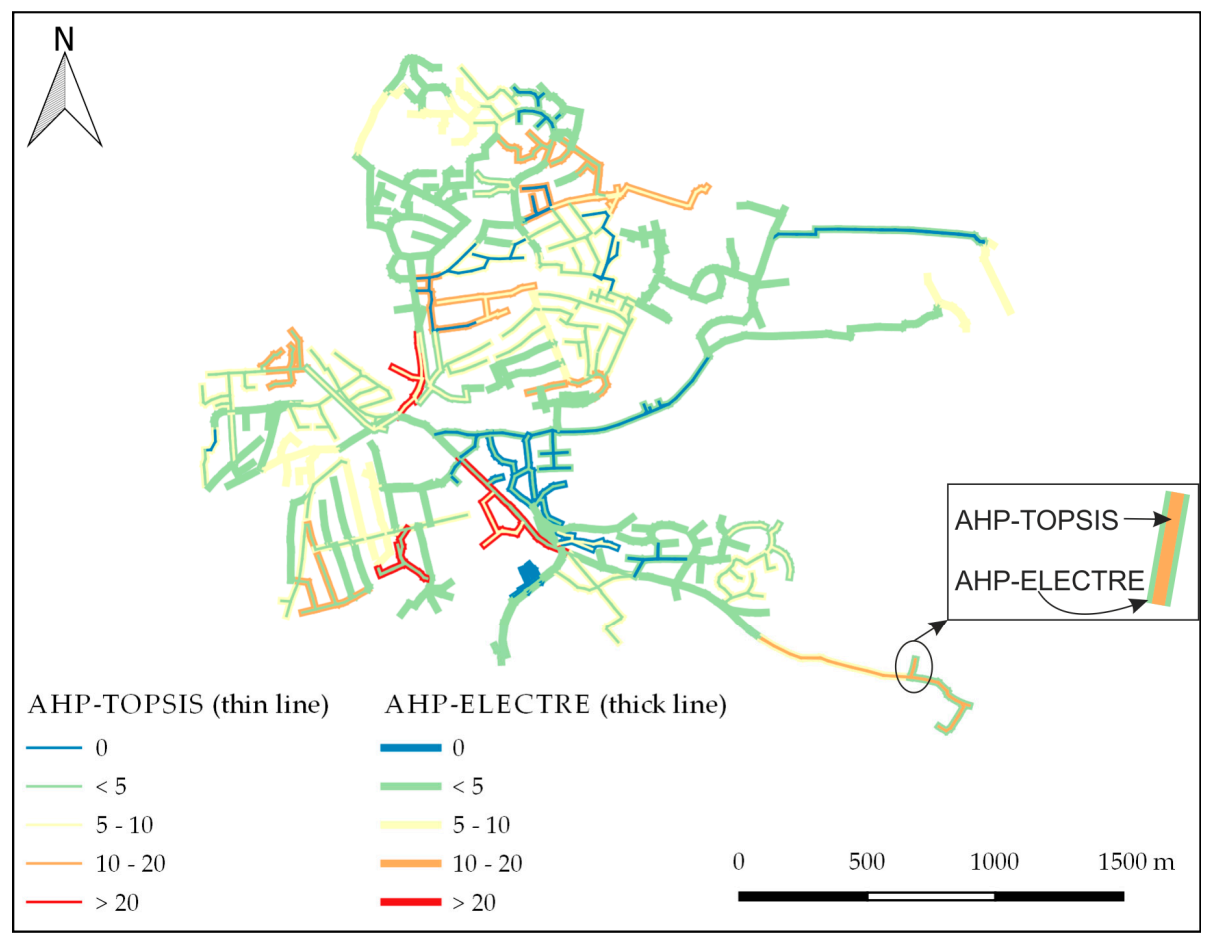

Figure 7. Comparison of the rankings of the sewer system between TOPSIS (thin line) and ELECTRE (thick line) with the results from AHP.

Comparing the AHP and PROMETHEE methods (Figure 6b) shows that the results are similar. In more than the half of the sewer network (51\%), the ranking difference is negligible between 0 and 2 ranks. In only 5 street sections the ranking difference is 10 or higher. These variations can be attributed to the differences between the AHP and outranking methods combined with the used score scales and weights. Especially in the case that a street section has a proportional small score in one or more criteria which is highly weighted, a difference between the two methods can occur.

It can be seen that in the $57.3 \%$ of the sewer network, the ranking difference between TOPSIS and AHP is negligible between 0 and 2 ranks (Figure $6 \mathrm{~b}$ ). Only in five street sections, the ranking difference is higher than 6 ranks. Thus, for the sewer network, the results of the AHP and TOPSIS show the largest similarities. The street sections in which the largest difference occurs are compared to the other methods ranked higher when using the TOPSIS method (see Figure 7). This is caused by the fact that in order to calculate the Euclidean distance of alternatives ideal and anti-ideal points are necessary. The values of the two parameters depend on the maximum (minimum) score of each criterion, but also on the distribution of the scores and their weights because they are normalized. A totally equal value of the range causes that equal score differences in these criteria have also the same impact on the result. Therefore, it may also be understood as the final weighting for this criterion, which describes the relevance of the score to the result. Hence, for the sewer network similar score differences in the criteria "material", "hydraulic capacity" and "economics" have equal importance. However, using the other methods (specially the AHP), the criteria "material" and "age" have the largest impact.

Figure $6 \mathrm{c}$ shows the differences between the WSM and the other models. Interestingly, given the fact that it is a quite simple model, the differences prove to be quite small (see Table 5). However, from the same group of outranking methods, the differences between ELECTRE and PROMETHEE are larger (see Figure $6 \mathrm{~d}$ and Table 5). Until the calculation of the concordance index $c_{j}(a, b)$ of the ELECTRE method and the preference index $p_{j}(a, b)$ of the PROMETHEE method, these two methods are similar if the same parameters $\mathrm{p}$ and $\mathrm{q}$ are used, as done in this paper, since, the relation between these two indices is $p_{j}(a, b)=1-c_{j}(a, b)[13]$. These methods differ when calculating the positive and negative flows in PROMETHEE, and when calculating the outranking degree $\mathrm{S}(\mathrm{a}, \mathrm{b})$ and constructing 
the preorder $\mathrm{Z}$ using the ELECTRE method. The largest differences (up to 28 ranks) occur in street sections which have at least one high weighted score which is really good and another one which is really bad. In this case ranking reverse [41] occurred. In the presented case study, the ranking difference between the two (descending and ascending) distillations [40] is up to 55 ranks. Since the ELECTRE uses the average from the two preorders (descending and ascending), the final rank of these special street sections is quite low, because of the result of the descending distillation process. It is lower than using the other methods, explaining the differences in Table 5 . The differences between TOPSIS and ELECTRE are similar to the ones between AHP and ELECTRE amplified with the differences between AHP and TOPSIS.

For analyzing the impact of the weights on the prioritization a sensitivity analysis was conducted. This was done by changing one weight until the highest-ranked street section in the preference ranking changes, while all the other weights are kept constant [69]. Figure 8 demonstrates the stability intervals of the different criteria and methods of the sewer network. The initial value of the weights is marked with a dot. The intervals show the range in which the weight can be varied without changing the highest ranked street sections. It can be observed that some criteria and methods are more sensitive than the others. For instance, the criteria "age" and "economics" of the sewer network are very stable for all the methods. However, the criteria "diameter" (stable using the PROMETHEE method), "pipe type", "house connections" and "manholes" are more sensitive for the majority of the methods. It can also be seen that the sensitivity of the parameters of the sewer depends also on the used methods.

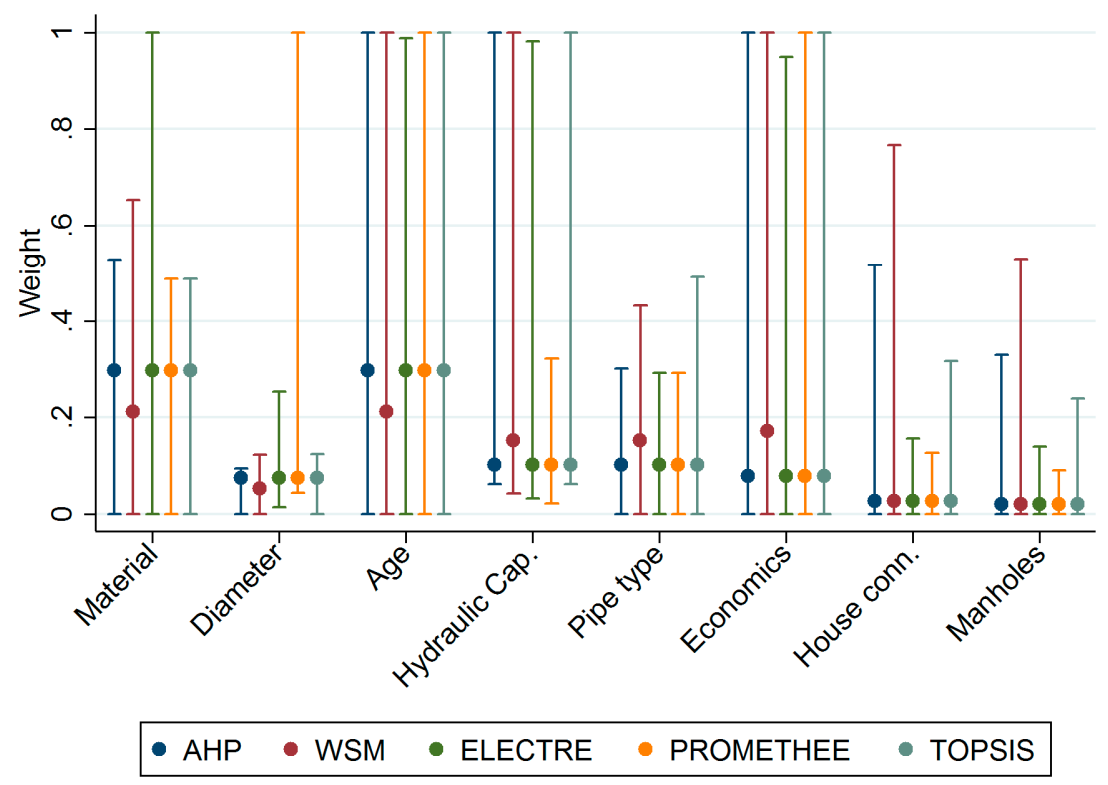

Figure 8. Sensitivity analysis for the sewer network.

\subsection{Water Distribution Network}

In Figure 5a, the preference ranking according to the AHP method is shown. It can be observed that the main interest of the water network is located in the central-north part of the system and in the southwest area. Figure 9a shows the highest ranking positions of the street sections obtained with the AHP method in comparison with the rankings obtained with the other four methods. In contrast to Figure 6a, which shows this comparison for the sewer network, none of the methods fit really well for the observed street sections. Comparing only these 10 street sections, the WSM and AHP show the highest level of similarities (range for the WSM 1-16). It is striking that the deviations of the other three methods occur mostly for the same street sections (for example street sections A and BU). Nevertheless, the largest differences appear between AHP and ELECTRE (see Table 6 and Figure 10). Using the 
PROMETHEE method, the street sections are ranked in the range of 1-16 (except the outlier BU), and when using the TOPSIS, they are ranked in a range of 1-15 (except the outlier BU).
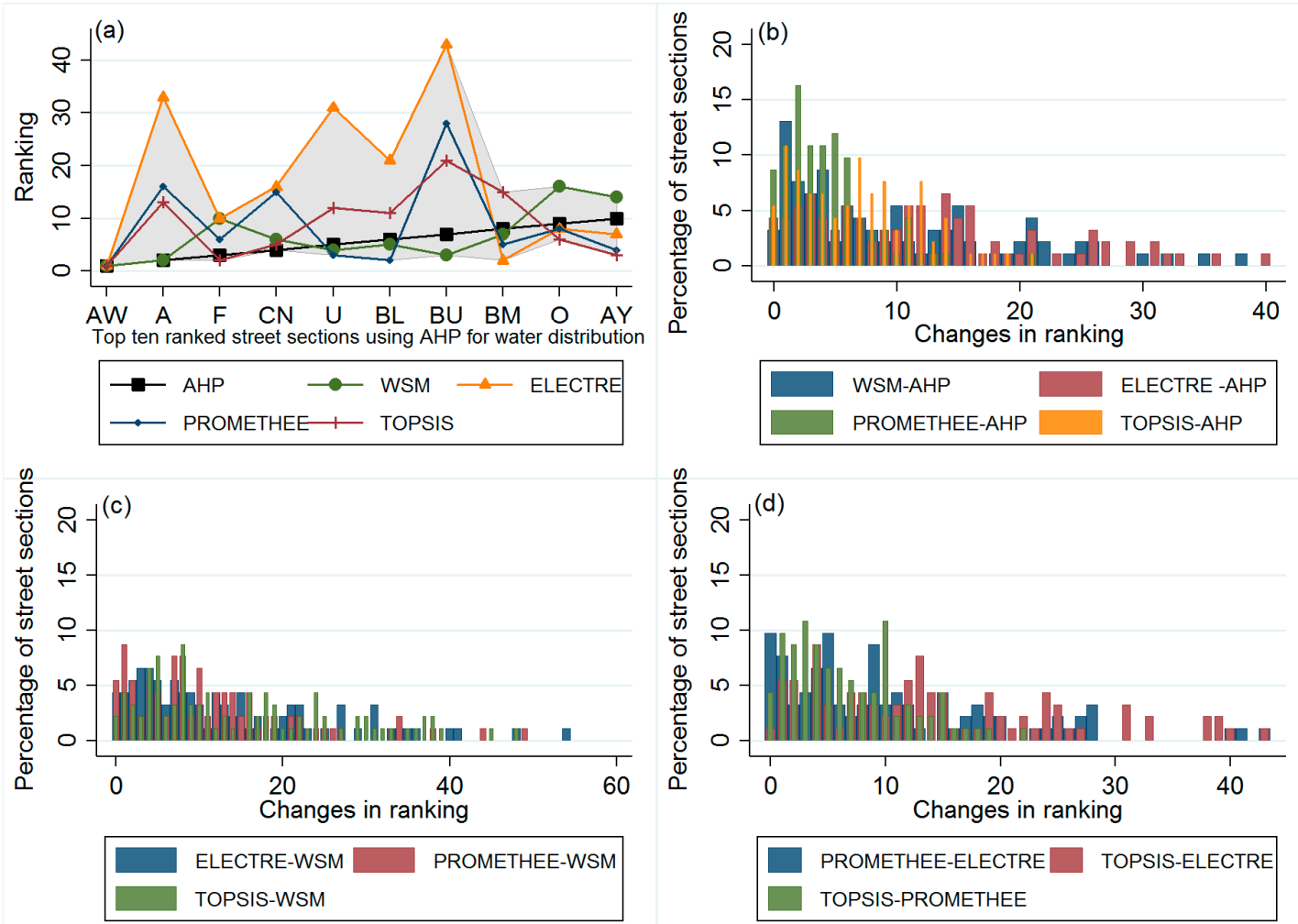

Figure 9. Comparison of the rankings of the water distribution system using the different methods: (a) for the 10 top ranked street sections; (b) the absolute ranking differences with the AHP; (c) the absolute ranking differences with the WSM; and (d) the absolute ranking differences with ELECTRE and PROMETHEE.

Table 6. Standard deviation $\sigma$ of the water distribution network ranking between the different used methods.

\begin{tabular}{|c|c|c|c|c|c|}
\hline$\sigma$ & AHP & WSM & ELECTRE & PROMETHEE & TOPSIS \\
\hline AHP & 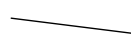 & 10.04 & 12.41 & 4.48 & 6.89 \\
\hline WSM & & 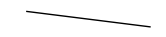 & 13.35 & 11.33 & 15.22 \\
\hline ELECTRE & & & 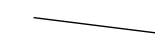 & 10.57 & 14.67 \\
\hline $\begin{array}{c}\text { PROMETHEE } \\
\text { TOPSIS }\end{array}$ & & symmetric & & 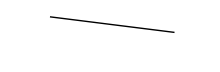 & 6.74 \\
\hline
\end{tabular}

Comparing the rankings of the water distribution obtained with the WSM and AHP, only in 23.9\% of the network ranking differences between 0 and 2 ranks are negligible. As can be seen in Figure $9 b$, in over $40 \%$ of the street sections have ranking differences of 10 ranks or higher. These significant differences can be attributed to the differences of the weights. Thus, for example, scores in the criteria "material" and "age" have a 40\% and 37\% higher influence when using the AHP method. Therefore, it occurs that street sections with low scores in these criteria are ranked higher if the WSM method is used. This happens often with street sections which contain manly pipes built with ductile iron (DI) or PVC. Looking at the criterion "age", it may happen that lower scores generate a higher ranking if the WSM method is used, whereas street sections with older pipe materials and therefore a higher score on this criterion are ranked higher if the AHP method is used. 


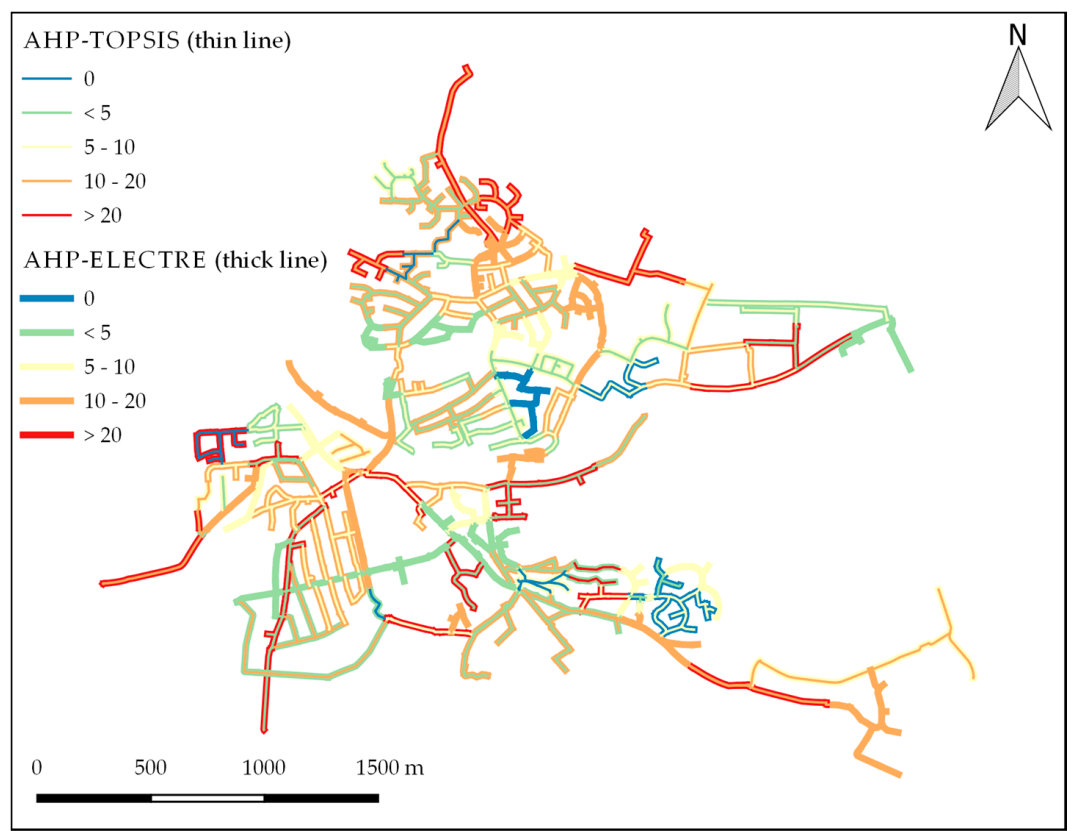

Figure 10. Comparison of the rankings of the water distribution system between TOPSIS (thin line) and ELECTRE (thick line) with the results from AHP.

In Figure $9 \mathrm{~b}$ can also be seen that the results of the AHP and PROMETHEE methods fit quite well: in $36.9 \%$ of the system the ranking differences between 0 and 2 ranks are negligible. Only in the $8.7 \%$ (8 street sections) of the network ranking differences of 10 ranks or higher occur. For the water network, these two methods show the highest level of similarities (see also Table 6). Nevertheless, the differences which appear occur due to same reasons as for the sewer network. For the water distribution, particularly pipes with low values in the criterion "material", which is weighted with 0.21 , are ranked higher when using the AHP method, since the average score is low.

Whereas for the sewer network the TOPSIS and the AHP results had more similarities to the PROMETHEE, it is reversed in the water network. It can be seen in Figure $9 \mathrm{~b}$ that in $24 \%$ of the system the ranking difference is between 0 and 2 ranks, whereas in the $27 \%$ the ranking difference is at least 10 ranks. The different distributions of the scores within each criterion are influencing on the result of the TOPSIS even more than on the other methods. Therefore, scores in the criteria "material", "age" and especially "economics" have an outstanding influence on the result.

Figure 9c shows the differences between the WSM and the other models. Interestingly, and in contrast to the findings for the sewer network, the differences prove to be larger (see Table 6). Figure 9d shows that the differences between the two outranking methods are not negligible. These differences result due to the occurring ranking reverse obtained when the two distillations are made, as described for the sewer network.

When applying the same sensitivity analysis as for the sewers it can be observed that for this network, the sensitivity does not depend so much on the used method. Moreover, four stable and five unstable criteria exist. The criteria "material", "diameter", "age" and "economics" are stable with all the methods (except ELECTRE for the criterion "economics"). Consequently, changing the weights of these criteria has no influence on the highest ranked street section AW. However, the increase of the weights of the other criteria might change the ranking order.

\subsection{Gas Distribution Network}

Figure $5 \mathrm{c}$ shows the preference rankings for the gas distribution network. It can be observed that the main interest area for this network is situated in the central and central-north part of the system. However, some individual street sections in the west and east of the system are considered. 
Figure 11a shows the highest ranking positions of the street sections obtained with the AHP method in comparison with the rankings of the other four methods. It is noticeable that the first four street sections are ranked equal regardless if AHP, ELECTRE or PROMETHEE methods are used. The AHP and PROMETHEE results fit generally well over the street sections (see also Table 7). Comparing the AHP and ELECTRE rankings, two outliers are visible, whereas the remaining ranking is similar. Using the WSM and due to the different weights, the observed street sections are ranked between 1 and 20. In addition, the preference ranking made with the TOPSIS has not many similarities with the AHP ranking. There are only five of these street sections located in the top 10.
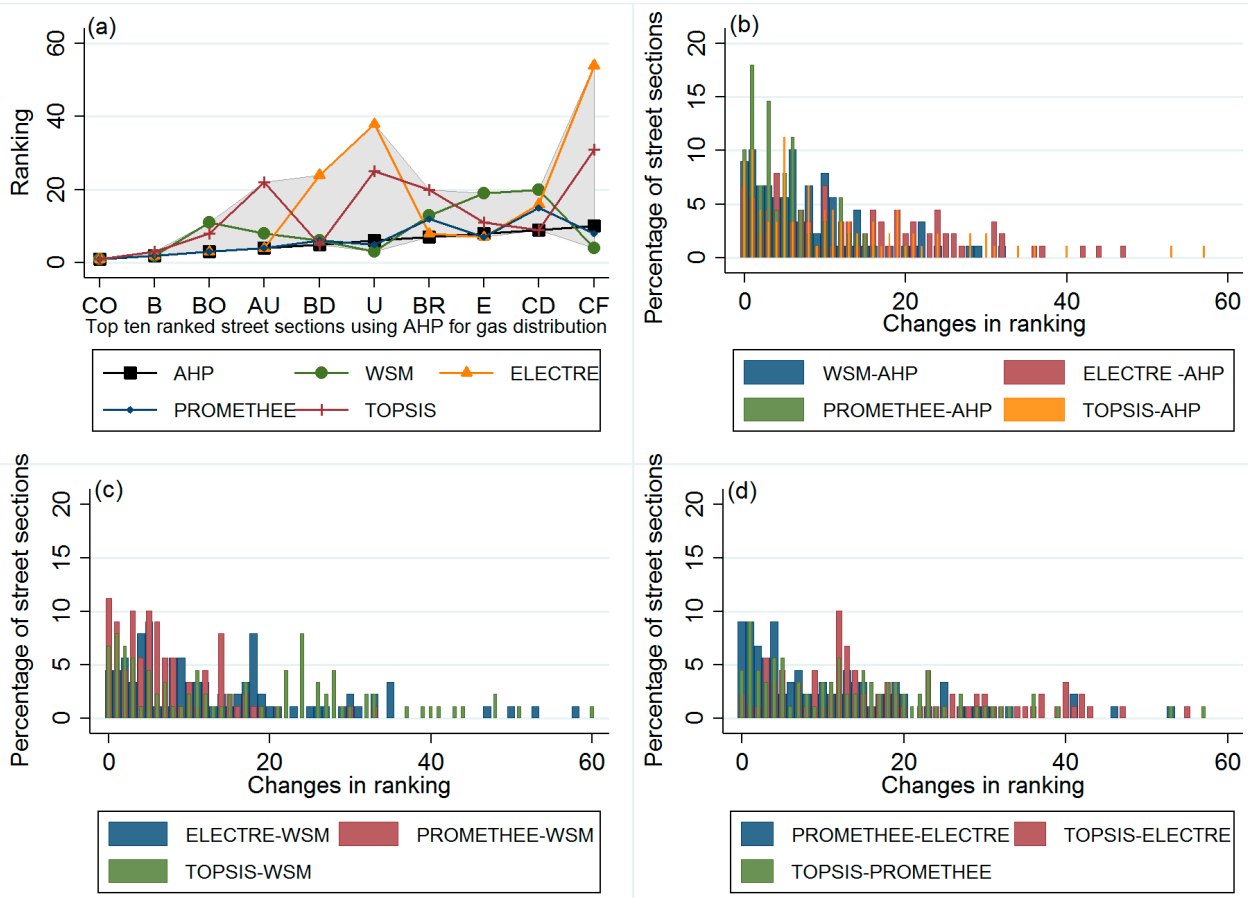

Figure 11. Comparison of the rankings of the gas distribution system using the different methods: (a) for the 10 top ranked street sections; (b) the absolute ranking differences with the AHP; (c) the absolute ranking differences with the WSM; and (d) the absolute ranking differences with ELECTRE and PROMETHEE.

Table 7. Standard deviation $\sigma$ of the gas distribution network ranking between the different used methods.

\begin{tabular}{|c|c|c|c|c|c|}
\hline$\sigma$ & AHP & WSM & ELECTRE & PROMETHEE & TOPSIS \\
\hline AHP & - & 7.86 & 14.20 & 5.08 & 11.53 \\
\hline WSM & & -000 & 13.84 & 7.06 & 16.67 \\
\hline ELECTRE & & & - & 11.37 & 18.43 \\
\hline $\begin{array}{c}\text { PROMETHEE } \\
\text { TOPSIS }\end{array}$ & & symmetric & & - & 13.80 \\
\hline
\end{tabular}

Since the differences between the used methods and the reasons were described for the drainage and water supply networks and also apply for the gas network, at this point just the differences for the gas distribution network are shown in Figures 11 and 12 and Table 7. In addition, for the sensitivity analysis of this network, the stability of the weights does not depend so strong on the used method. Comparing the three networks, the gas network is the most stable one. Only an increase of the weights in the criteria "house connections" and "manholes" have for all the methods the most significant effect on the ranking position of the highest ranked street section CO. 


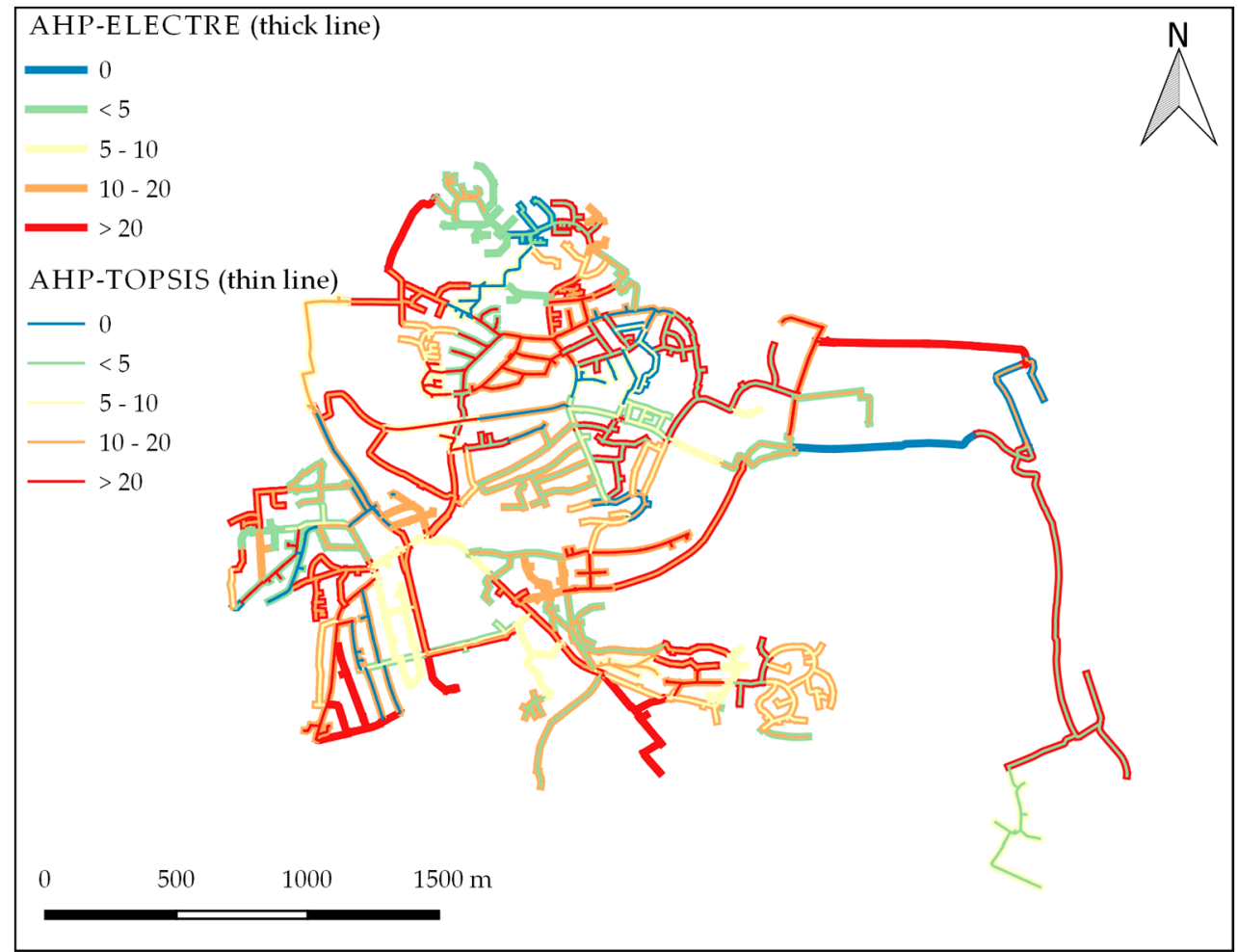

Figure 12. Comparison of the rankings of the gas distribution system between TOPSIS (thin line) and ELECTRE (thick line) with the results from AHP.

\subsection{Integrated Prioritization}

It can be seen in Figure $5 \mathrm{~d}$ that the main interests for the whole network are situated in the northern area of the system. However, the central-south area is important, as well as individual street sections in the west and east area of the system.

Figure 13a shows the highest ranking positions of the street sections obtained with the AHP method in comparison with the rankings of the other four methods. It is noticeable that the first three street sections are ranked equal if AHP or WSM are used; the same first rank is obtained by TOPSIS. The AHP and PROMETHEE results fit generally all well over the street sections. Comparing the AHP and ELECTRE rankings, four major outliers are visible, whereas the remaining ranking is similar. Comparing the total ranking of the different methods (Table 8), it can be seen that the rankings of the AHP and PROMETHEE methods have the largest similarities (see Figure 13b). Comparing ELECTRE (see Figures 13b-d and 14) with other methods, for example with PROMETHEE, large differences are visible. These differences mostly result from the ranking reverse when using ELECTRE, which was described before. In addition, comparing the total ranking of the WSM and AHP methods, large differences can be seen. They result from the different weights used.

Table 8. Standard deviation $\sigma$ of the integrated ranking between the different used methods.

\begin{tabular}{|c|c|c|c|c|c|}
\hline$\sigma$ & AHP & WSM & ELECTRE & PROMETHEE & TOPSIS \\
\hline AHP & - & 9.50 & 14.79 & 4.46 & 9.15 \\
\hline WSM & & 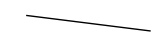 & 14.79 & 9.67 & 16.08 \\
\hline ELECTRE & & & - & 12.58 & 16.88 \\
\hline $\begin{array}{c}\text { PROMETHEE } \\
\text { TOPSIS }\end{array}$ & & symmetric & & 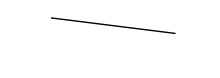 & 10.31 \\
\hline
\end{tabular}



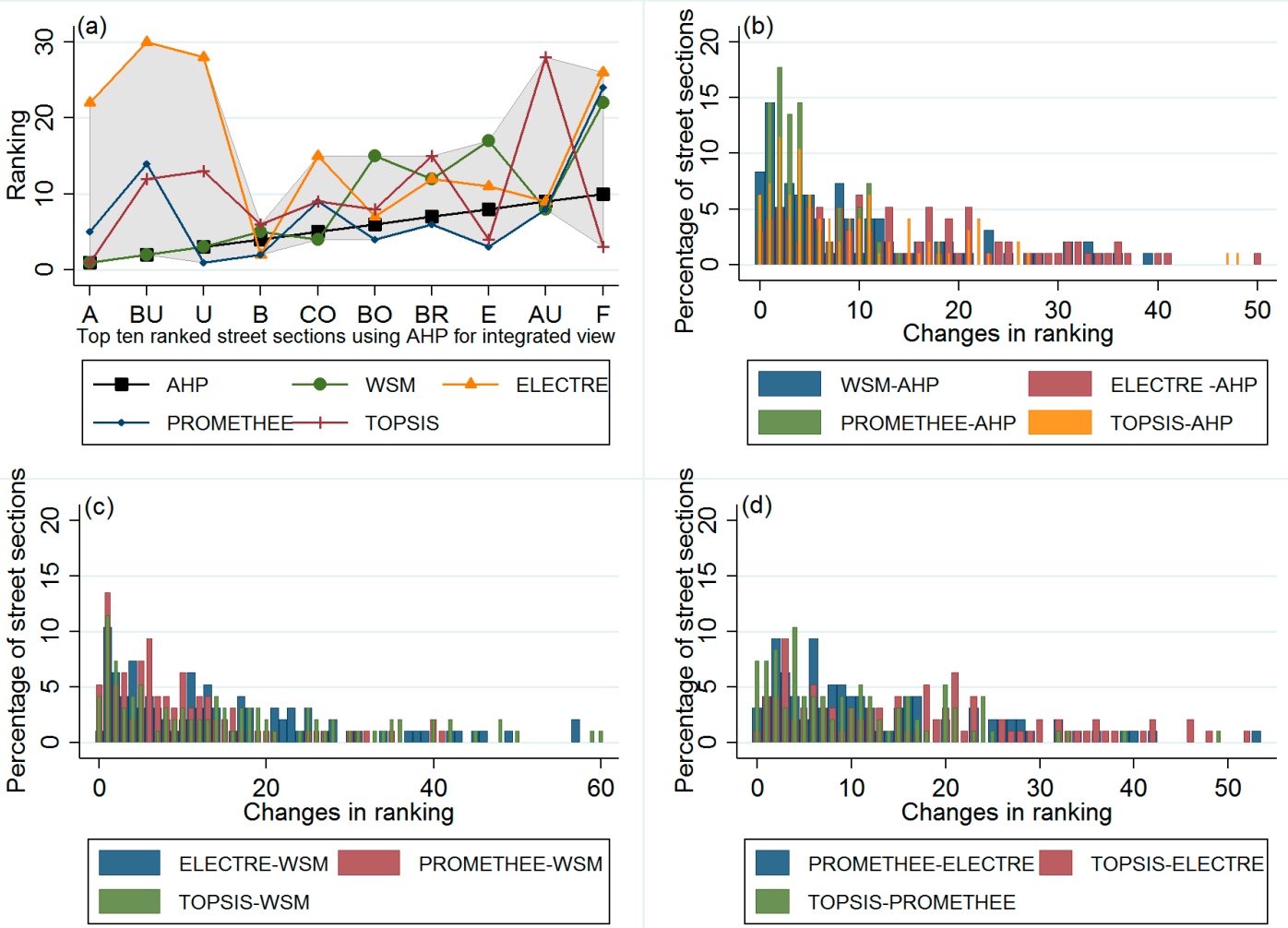

Figure 13. Comparison of the rankings of the integrated prioritization using the different methods: (a) for the 10 top ranked street sections; (b) the absolute ranking differences with the AHP; (c) the absolute ranking differences with the WSM; and (d) the absolute ranking differences with ELECTRE and PROMETHEE.

For sensitivity analysis, a random sampling of the used weights for the four networks from a uniform distribution (using 100,000 weight samples), under the condition that they sum up to $100 \%$, was applied [70]. The results of this sensitivity analysis to estimate the stability of the total ranking is shown here (see Figure 15) for the 10 highest ranked street sections of the AHP method. The AHP method is chosen because its results fit best in overall with the results of the other methods. Therefore, it best represents the behavior of the used methods. Figure 15 shows the result of this analysis. Particularly, the four highest ranked street sections (A, BU, U and B) but also CO and BR in the 5th and 7th position are stable for the variation of the weights. The high stability of the two highest ranked street sections can be attributed to the fact that these two street sections only appear in two of the networks and they are ranked high for those networks, especially for the water network. The robustness of the other street sections is caused by the high rankings in all the networks. The four street sections BO, E, AU and F are more sensitive to the variation of the weights. Their median is not within the top 10 ranked street sections from the AHP method. These four street sections are not ranked in the top 40 of the sewer network and this network is weighted with 0.10 for calculating the total ranking. Especially after doubling this weight $(>0.20)$, these four street sections are not ranked anymore in the top ten of the total ranking. Hence, the definition of the weights has for these four street sections a large impact and therefore they have to be chosen carefully. 


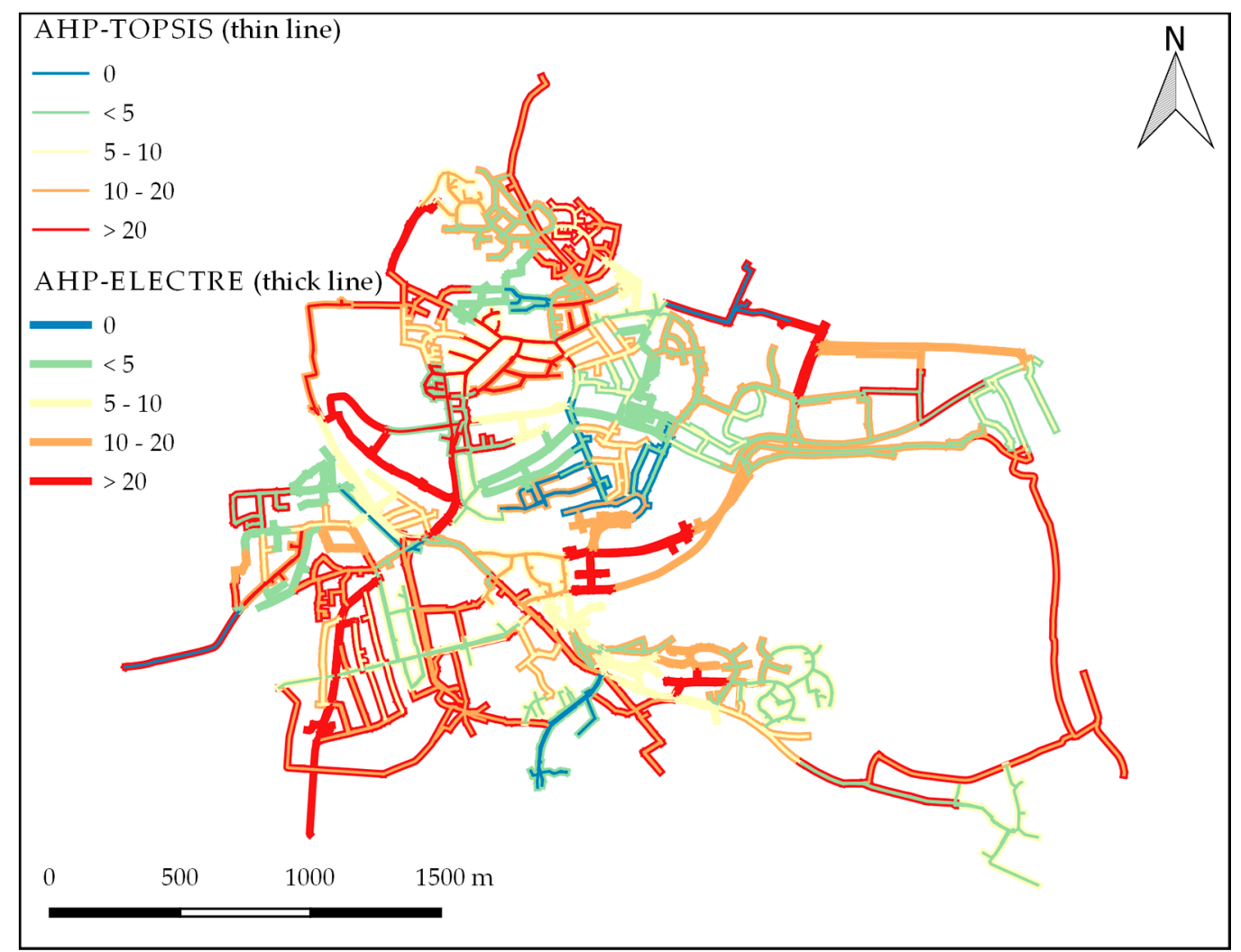

Figure 14. Comparison of the rankings of the integrated prioritization between TOPSIS (thin line) and ELECTRE (thick line) with the results from AHP.

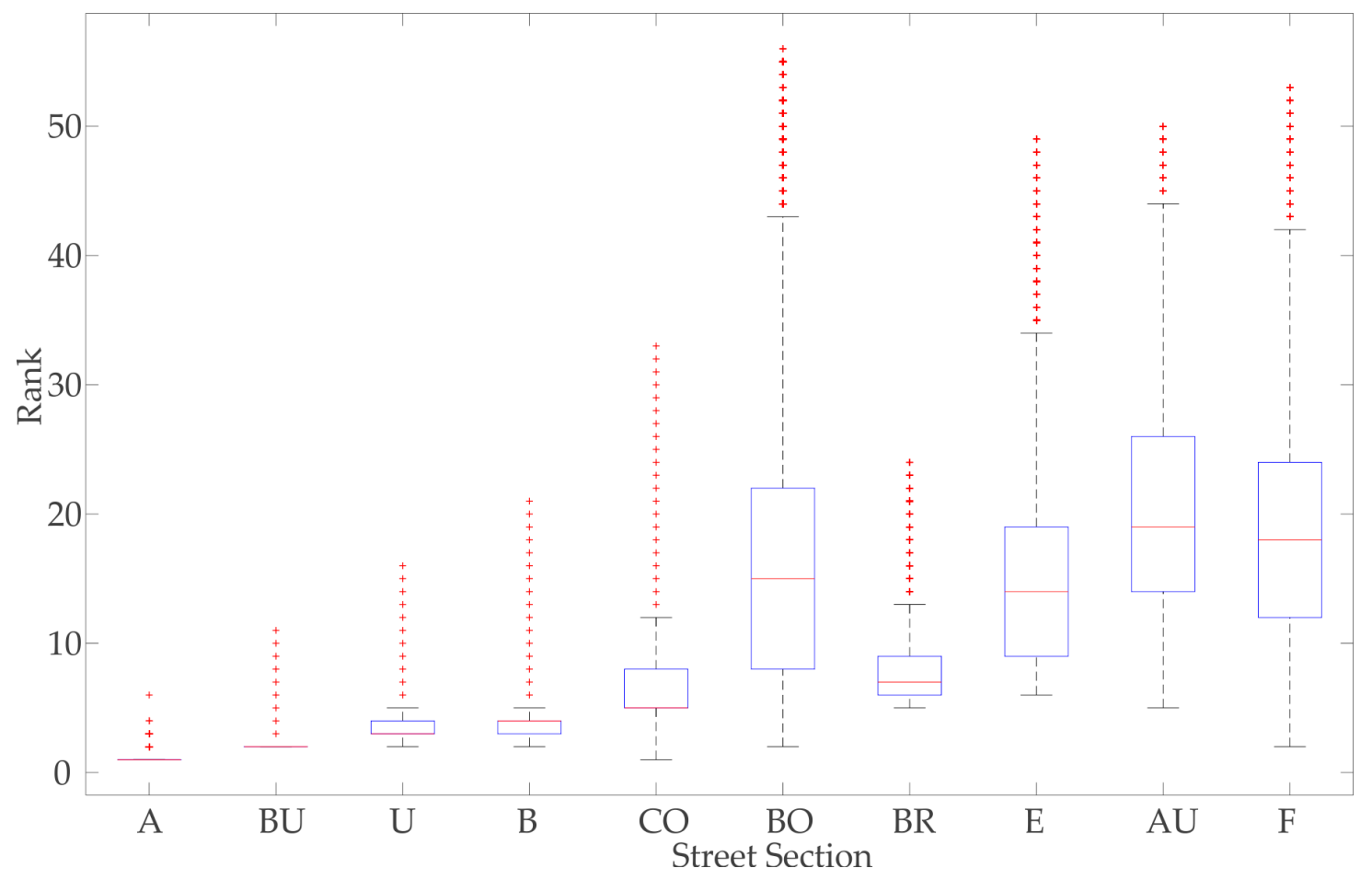

Figure 15. Sensitivity analysis for the total network for the AHP. 
To show the impact of the selection of the scores the results are compared to another approach using the same data [10]. The main differences were the missing subdivision of data into main categories and the usage of another MCDM approach, namely a revised version of the VIKOR multi-criteria optimization and compromise solution method [71]. The differences in data subdivision were mainly caused by the fact that the categories (e.g., "material") were not classified into main categories (e.g., condition), before being implemented into the method. This complicated the weighting as more influencing factors had to be compared pairwise at once. Further, for the sewer system, no differentiation between the two worst condition classes were made. Even though both approaches were started using the same data, the assumptions regarding influencing factors and scores were therefore partly different. Due to the fact, that the usage of another MCDM method would have an effect on the result the rank differences were expected to be larger than before. However the differences of the used method alone could not explain the enormous impact on the results, as can be seen in Figure 16, especially as other studies [24] showed VIKOR to behave similarly to the AHP method. This shows the enormous impact of the selection of scores on the results and underlines how important their definition is in the beginning. These considerations have an immense influence on the results.

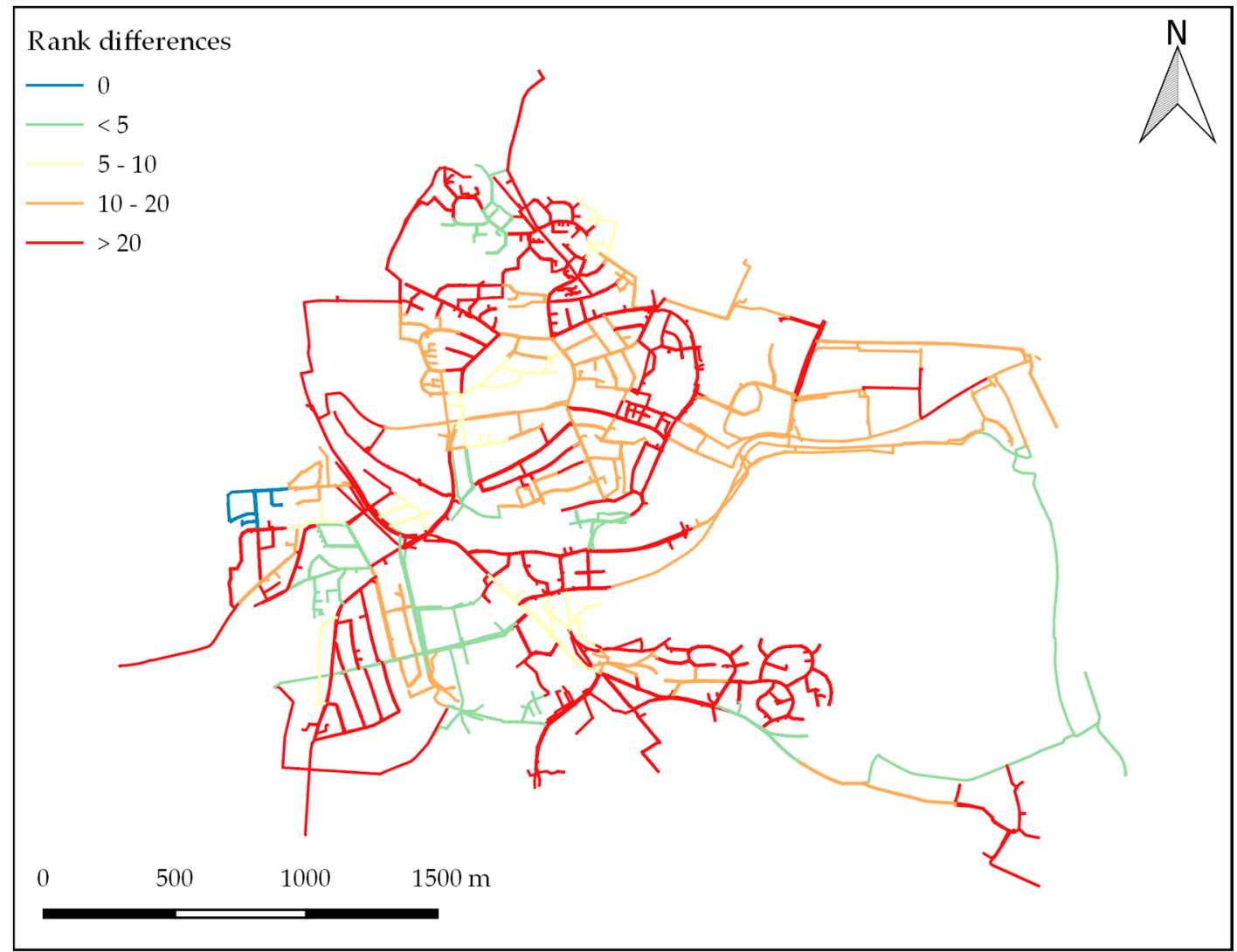

Figure 16. Comparison of the results of the AHP approach with a different approach with different scores [10].

\section{Conclusions}

After comparing the results and making the sensitivity analysis, it can be stated that the results of the different methods are not equal. This is because the chosen score scales and the resulting distributions of the scores within the criteria do not have the same impact on all the methods. In addition, the defined weights have a large effect on the result. This was observed when the WSM and AHP methods were compared, and when the sensitivity analysis was carried out. It was 
also shown how large the differences between the weights defined by experts can be. Therefore, it is important to justify the definitions of the weights well.

However, all these mentioned factors do not have as much influence as the definition of the criteria and the related score scales. This is noticeable when the results of any used methods in this paper were compared with an earlier approach using different scoring algorithms [10]. Even though both approaches were started using the same data, the assumptions regarding influencing factors and scores were partly different. These differences had an enormous impact on the results. At this point, it is relevant to mention again that, particularly in the beginning of the decision making process, the decision maker needs to invest enough time in order to define the criteria. For the integrated rehabilitation management, this includes especially the identification of the influencing factors, the definition of the weights and the definition of the score scales. When the sensitivity analysis of the total network was developed, a problem of the integrated rehabilitation planning was observed. The two highest ranked street sections obtained with the AHP method were really stable, since they appeared only in two networks. Hence, the ranking positions of street sections which did not appear in every network did not represent the total network and they should be considered separately.

Another issue is which method provides the "correct" result or rather a transparent and comprehensible result (due to the fact that a "correct" result does not exist), which is even more important. This is given by all these used methods, since the results and also differences between the methods were always clear and comprehensible. For this case study with limited data, it was seen that simple methods such as the AHP gave results similar to the ones obtained with the complex outranking method PROMETHEE. Obviously, the main advantage of the AHP (and also WSM) is that these are simple and fast understandable methods for people who are not familiar with the multi-criteria decision support methods. Considering also the relatively small differences in the results compared to the PROMETHEE and TOPSIS (for the majority of the networks), the use of the AHP method could be sufficient in this case study. Especially in the rehabilitation planning, a ranking difference up to 5 ranks is negligible, considering that the pipe is replaced in an acceptable range of 2-3 years. This is however only true for pipes where no immediate endangerment to the environment is given (e.g., by sinkholes caused by collapsing sewer pipes or seeping of wastewater to groundwater). To avoid this problem, after prioritization another decision stage should be applied [10], enabling the rehabilitation of certain individual pipes without the entire street section. Nevertheless, the WSM and AHP methods reach their limits when too many criteria are involved. Therefore, TOPSIS could be a good option because it is suitable for a numerous number of criteria while maintaining a simple and easy understandable method. TOPSIS is, as the AHP and WSM, usable also without any special programming skills and can be easily implemented in a spreadsheet.

On the other hand, the outranking methods are a very powerful tool. Considering the definition of the thresholds of each criterion, the possibility of influencing for the decision maker is abundant. However, when applying these methods, experience and special programs or programming skills are required, which may be wasted when using limited data quality.

The creation of the model and the calculation of the preference ranking is only the first step. Afterwards, the resulting ranking has to be compared with the real system. An infrastructure network is not a static system, it changes constantly. Hence, the defined model needs to be reserved and adjusted routinely according to the real system. New failure data and the observed condition of the sewer have to be implemented frequently in the created model in order to keep the model up to date. Therefore, these used methods should only be applied to a real infrastructure system in cooperation with the operator.

Subsequently, the selection of the method to use for rehabilitation planning depends mainly on the available data and resources in time and manpower. In some cases, it would be rational to use one of the simplest methods [24], especially when the data quality is low and no external knowledge is available or affordable. For larger datasets with more influencing factors with better data quality, a more sophisticated method will provide valuable results. However, to check for consistency and increase the 
reliability of the results the application of several methods is encouraged [72]. Independently of the method used, the decision maker must be familiar with its strengths but also weaknesses [73]. In this regard, the selection and preprocessing of the input data for the different methods prove to be of the utmost importance.

Acknowledgments: This work is part of the project "FlexAdapt-Flexible concepts for the adaptation of urban water infrastructure" funded by the Austrian Federal Ministry of Agriculture, Forestry, Environment and Water Management.

Author Contributions: All authors substantially contributed in conceiving and designing of the approach and realizing this manuscript. Franz Tscheikner-Gratl and Patrick Egger prepared the input data. Patrick Egger implemented the multi-criteria decision models during his master thesis. Franz Tscheikner-Gratl and Patrick Egger worked on the analysis and presentation of the results. Manfred Kleidorfer and Wolfgang Rauch supervised the entire research. Franz Tscheikner-Gratl wrote the paper. All authors have read and approved the final manuscript.

Conflicts of Interest: The authors declare no conflict of interest.

\section{References}

1. European Committee for Standardization. European Standard EN 752. Drain and Sewer Systems Outside Buildings; ICS 93.030; Comite Europeen de Normalisation (CEN): Brussels, Belgium, 2008.

2. European Committee for Standardization. European Standard EN 805. Water Supply-Requirements for Systems and Components Outside Buildings; ICS 23.040.01; Comite Europeen de Normalisation (CEN): Brussels, Belgium, 2000.

3. Casillas, M.; Garza-Castañón, L.; Puig, V. Optimal Sensor Placement for Leak Location in Water Distribution Networks using Evolutionary Algorithms. Water 2015, 7, 6496-6515. [CrossRef]

4. Sörensen, J.; Persson, A.; Sternudd, C.; Aspegren, H.; Nilsson, J.; Nordström, J.; Jönsson, K.; Mottaghi, M.; Becker, P.; Pilesjö, P.; et al. Re-Thinking Urban Flood Management-Time for a Regime Shift. Water 2016, 8, 332. [CrossRef]

5. Sægrov, S. (Ed.) Care-W: Computer Aided Rehabilitation of Water Networks; IWA Publishing: London, UK, 2005.

6. Sægrov, S. (Ed.) Care-S: Computer Aided Rehabilitation of Sewer and Stormwater Networks; IWA Publishing: London, UK, 2006.

7. Yoo, D.; Kang, D.; Jun, H.; Kim, J. Rehabilitation Priority Determination of Water Pipes Based on Hydraulic Importance. Water 2014, 6, 3864-3887. [CrossRef]

8. Osman, H. Coordination of urban infrastructure reconstruction projects. Struct. Infrastruct. Eng. 2015, 12, 108-121. [CrossRef]

9. Tscheikner-Gratl, F.; Sitzenfrei, R.; Rauch, W.; Kleidorfer, M. Integrated rehabilitation planning of urban infrastructure systems using a street section priority model. Urban Water J. 2016, 13, 28-40. [CrossRef]

10. Tscheikner-Gratl, F.; Sitzenfrei, R.; Stibernitz, C.; Rauch, W.; Kleidorfer, M. Integrated rehabilitation management by prioritization of rehabilitation areas for small and medium sized municipalities. In Proceedings of the World Environmental and Water Resources Congress 2015: Floods, Droughts, and Ecosytems, Austin, TX, USA, 17-21 May 2015; Karvazy, K., Webster, V.L., Eds.; ASCE: Reston, VA, USA, 2015; pp. 2045-2057.

11. Zavadskas, E.K.; Turskis, Z.; Kildienè, S. State of art surveys of overviews on MCDM/MADM methods. Technol. Econ. Dev. Econ. 2014, 20, 165-179. [CrossRef]

12. Huang, I.B.; Keisler, J.; Linkov, I. Multi-criteria decision analysis in environmental sciences: Ten years of applications and trends. Sci. Total Environ. 2011, 409, 3578-3594. [CrossRef] [PubMed]

13. Belton, V.; Stewart, T.J. Multiple Criteria Decision Analysis; Springer: Boston, MA, USA, 2002.

14. Løken, E. Use of multicriteria decision analysis methods for energy planning problems. Renew. Sustain. Energy Rev. 2007, 11, 1584-1595. [CrossRef]

15. Tscheikner-Gratl, F. Integrated Approach for Multi-Utility Rehabilitation Planning of Urban Water Infrastructure: Focus on Small and Medium Sized Municipalities. Ph.D. Thesis, University Innsbruck, Innsbruck, Austria, 2016.

16. Kabir, G.; Sadiq, R.; Tesfamariam, S. A review of multi-criteria decision-making methods for infrastructure management. Struct. Infrastruct. Eng. 2014, 10, 1176-1210. [CrossRef] 
17. Mardani, A.; Jusoh, A.; MD Nor, K.; Khalifah, Z.; Zakwan, N.; Valipour, A. Multiple criteria decision-making techniques and their applications-A review of the literature from 2000 to 2014. Econ. Res.-Ekon. Istraž. 2015, 28, 516-571. [CrossRef]

18. Brownlee, T.J.; Finnie, S.; Wightman, D. Identification of potential highways maintenance schemes. Proc. Inst. Civ. Eng.-Transp. 2007, 160, 139-146. [CrossRef]

19. Tzeng, G.-H.; Huang, J.-J. Multiple Attribute Decision Making: Methods and Appliations; CRC Press: Boca Raton, FL, USA, 2011.

20. Saaty, T.L. Multicriteria Decision Making: The Analytic Hierarchy Process; Planning, Priority Setting, Resource Allocation, 2nd ed.; McGraw-Hill: New York, NY, USA, 1988.

21. Macharis, C.; Springael, J.; de Brucker, K.; Verbeke, A. PROMETHEE and AHP: The design of operational synergies in multicriteria analysis. Eur. J. Oper. Res. 2004, 153, 307-317. [CrossRef]

22. Al-Barqawi, H.; Zayed, T. Infrastructure Management: Integrated AHP/ANN Model to Evaluate Municipal Water Mains' Performance. J. Infrastruct. Syst. 2008, 14, 305-318. [CrossRef]

23. Birgani, Y.T.; Yazdandoost, F.; Dehlavi, E. Integrated Approach in Spatial Priority of Urban Areas for Implementation of Urban Drainage Plans Using Analytic Hierarchy Process and GIS for 22nd Municipal District of Tehran, Iran. In Proceedings of the 13th International Conference on Urban Drainage, Sarawak, Malaysia, 7-12 September 2014.

24. Sabzi, H.Z.; King, J.P. Numerical Comparison of Multi-criteria Decision-making Techniques: A Simulation on Flood Management Multi-criteria Systems. In Proceedings of the World Environmental and Water Resources Congress 2015: Floods, Droughts, and Ecosytems, Austin, TX, USA, 17-21 May 2015; Karvazy, K., Webster, V.L., Eds.; ASCE: Reston, VA, USA, 2015.

25. Lee, J.H.; Baek, C.W.; Kim, J.H.; Jun, H.D.; Jo, D.J. Development of a Decision Making Support System for Efficient Rehabilitation of Sewer Systems. Water Resour. Manag. 2009, 23, 1725-1742. [CrossRef]

26. Young, K.D.; Younos, T.; Dymond, R.L.; Kibler, D.F.; Lee, D.H. Application of the Analytic Hierarchy Process for Selecting and Modeling Stormwater Best Management Practices. J. Contemp. Water Res. Educ. 2010, 146, 50-63. [CrossRef]

27. Feizizadeh, B.; Jankowski, P.; Blaschke, T. A Spatially Explicit Approach for Sensitivity and Uncertainty Analysis of GIS-Multicriteria Landslide Susceptibility Mapping. In GI_Forum 2013_Creating the GISociety; Jekel, T., Car, A., Strobl, J., Griesebner, G., Eds.; ÖAW Verlag: Vienna, Austria, 2013; pp. 157-164.

28. Feizizadeh, B.; Omrani, K.; Aghdam, F.B. Fuzzy Analytical Hierarchical Process and Spatially Explicit Uncertainty Analysis Approach for Multiple Forest Fire Risk Mapping. GI-Forum 2015, 1, 72-80. [CrossRef]

29. Benayoun, R.; Roy, B.; Sussman, N. Manual de Reference du Programme Electre; SEMA: Paris, France, 1966.

30. Mardani, A.; Jusoh, A.; Zavadskas, E.K. Fuzzy multiple criteria decision-making techniques and applications-Two decades review from 1994 to 2014. Expert Syst. Appl. 2015, 42, 4126-4148. [CrossRef]

31. Govindan, K.; Jepsen, M.B. ELECTRE: A comprehensive literature review on methodologies and applications. Eur. J. Oper. Res. 2016, 250, 1-29. [CrossRef]

32. Baur, R.; Herz, R.; Kropp, I. WP6-Multi-Criteria Decision Support: WP6 Conclusive Report; CARE-S Computer Aided REhabilitation of Sewer networks: Dresden, Germany, 2005.

33. Carrico, N.; Covas, D.I.C.; Almeida, M.C.; Leitao, J.P.; Alegre, H. Prioritization of rehabilitation interventions for urban water assets using multiple criteria decision-aid methods. Water Sci. Technol. J. Int. Assoc. Water Pollut. Res. 2012, 66, 1007-1014. [CrossRef] [PubMed]

34. Moura, P.M.; Baptista, M.B.; Barraud, S. Comparison between two methodologies for urban drainage decision aid. Water Sci. Technol. 2006, 54, 493. [CrossRef] [PubMed]

35. Martin, C.; Ruperd, Y.; Legret, M. Urban stormwater drainage management: The development of a multicriteria decision aid approach for best management practices. Eur. J. Oper. Res. 2007, 181, 338-349. [CrossRef]

36. Haider, H.; Sadiq, R.; Tesfamariam, S. Selecting performance indicators for small and medium sized water utilities: Multi-criteria analysis using ELECTRE method. Urban Water J. 2013, 12, 305-327. [CrossRef]

37. Morais, D.C.; Almeida, A.T. Water supply system decision making using multicriteria analysis. Water $S A$ 2007, 32, 229-236. [CrossRef]

38. Le Gauffre, P.; Haidar, H.; Poinard, D.; Laffréchine, K.; Baur, R.; Schiatti, M. A Multicriteria Decision Support Methodology for Annual Rehabilitation Programs of Water Networks. Comput.-Aided Civ. Eng. 2007, 22, 478-488. [CrossRef] 
39. Trojan, F.; Morais, D.C. Prioritising alternatives for maintenance of water distribution networks: A group decision approach. Water SA 2012, 38. [CrossRef]

40. Buchanan, J.; Vanderpooten, D. Ranking projects for an electricity utility using ELECTRE III. Int. Trans. Oper. Res. 2007, 14, 309-323. [CrossRef]

41. Pires, A.; Chang, N.-B.; Martinho, G. An AHP-based fuzzy interval TOPSIS assessment for sustainable expansion of the solid waste management system in Setúbal Peninsula, Portugal. Resour. Conserv. Recycl. 2011, 56, 7-21. [CrossRef]

42. Brans, J.-P.; Mareschal, B. The PROMCALC \& GAIA decision support system for multicriteria decision aid. Decis. Support Syst. 1994, 12, 297-310.

43. Behzadian, M.; Kazemzadeh, R.B.; Albadvi, A.; Aghdasi, M. PROMETHEE: A comprehensive literature review on methodologies and applications. Eur. J. Oper. Res. 2010, 200, 198-215. [CrossRef]

44. Brans, J.P. L'ingénièrie de la décision; Elaboration d'instruments d'aide à la décision. La méthode PROMETHEE. In L'aide à la Décision: Nature, Instruments et Perspectives d'Avenir; Nadeau, R., Landry, M., Eds.; Presses de l’Université Laval: Ville de Québec, QC, Canada, 1982; pp. 183-213.

45. Brans, J.P.; Vincke, P. A Preference Ranking Organisation Method: (The PROMETHEE Method for Multiple Criteria Decision-Making). Manag. Sci. 1985, 31, 647-656. [CrossRef]

46. Gervásio, H.; Simões da Silva, L. A probabilistic decision-making approach for the sustainable assessment of infrastructures. Expert Syst. Appl. 2012, 39, 7121-7131. [CrossRef]

47. Churchman, C.W.; Ackoff, R.L.; Smith, N.M. An Approximate Measure of Value. J. Oper. Res. Soc. Am. 1954, 2, 172-187. [CrossRef]

48. Tscheikner-Gratl, F.; Sitzenfrei, R.; Hammerer, M.; Rauch, W.; Kleidorfer, M. Prioritization of Rehabilitation Areas for Urban Water Infrastructure. A Case Study. Procedia Eng. 2014, 89, 811-816. [CrossRef]

49. Kolios, A.; Mytilinou, V.; Lozano-Minguez, E.; Salonitis, K. A Comparative Study of Multiple-Criteria Decision-Making Methods under Stochastic Inputs. Energies 2016, 9, 566. [CrossRef]

50. Coutinho-Rodrigues, J.; Simão, A.; Antunes, C.H. A GIS-based multicriteria spatial decision support system for planning urban infrastructures. Decis. Support Syst. 2011, 51, 720-726. [CrossRef]

51. Ochs, C.-P. Multikriterielle Optimierung der Sanierungsplanung von Entwässerungsnetzen. Ph.D. Thesis, Technische Universität Kaiserslautern, Kaiserslautern, Germany, 2012.

52. Triantaphyllou, E.; Sánchez, A. A Sensitivity Analysis Approach for Some Deterministic Multi-Criteria Decision-Making Methods. Decis. Sci. 1997, 28, 151-194. [CrossRef]

53. Hwang, C.L.; Yoon, K. Multiple Attribute Decision Making: Methods and Applications A State-of-the-Art Survey; Springer: Berlin/Heidelberg, Germany, 1981.

54. Behzadian, M.; Khanmohammadi Otaghsara, S.; Yazdani, M.; Ignatius, J. A state-of the-art survey of TOPSIS applications. Expert Syst. Appl. 2012, 39, 13051-13069. [CrossRef]

55. Rao, R.V. Decision Making in the Manufacturing Environment: Using Graph Theory and Fuzzy Multiple Attribute Decision Making Methods; Springer: London, UK, 2007.

56. Alegre, H.; Coelho, S.T. Infrastructure Asset Management of Urban Water Systems. In Water Supply System Analysis—Selected Topics; Ostfeld, A., Ed.; Intech: Rijeka, Croatia, 2012; pp. 49-73.

57. Baker, D.; Bridge, D.; Hunter, R.; Johnon, G.; Krupa, J.; Murphy, J.; Sorenson, K. Guidebook to Decision Making Methods; United States Department of Energy: Washington, DC, USA, 2001.

58. Van Riel, W.; van Bueren, E.; Langeveld, J.; Herder, P.; Clemens, F. Decision-making for sewer asset management: Theory and practice. Urban Water J. 2015, 13, 57-68. [CrossRef]

59. Van Riel, W.; Langeveld, J.G.; Herder, P.M.; Clemens, F. Intuition and information in decision-making for sewer asset management. Urban Water J. 2013, 11, 506-518. [CrossRef]

60. Tscheikner-Gratl, F.; Sitzenfrei, R.; Rauch, W.; Kleidorfer, M. Enhancement of limited water supply network data for deterioration modelling and determination of rehabilitation rate. Struct. Infrastruct. Eng. 2016, 12, 366-380. [CrossRef]

61. Österreichischer Wasser- und Abfallwirtschaftsverband. ÖWAV-Regelblatt 40/ÖVGW Richtlinie W 104: Leitungsinformationssystem; Wasser und Abwasser: Vienna, Austria, 2010.

62. Deutsche Vereinigung für Wasserwirtschaft. DWA-Merkblatt DWA-M 149-3. DWA-M 149-3: Zustandserfassung und -Beurteilung von Entwässerungssystemen außerhalb von Gebäuden-Teil 3: Zustandsklassifizierung und -Bewertung; Abwasser und Abfall e.V.: Hennef, Germany, 2007. 
63. Ariaratnam, S.T.; El-Assaly, A.; Yang, Y. Assessment of Infrastructure Inspection Needs Using Logistic Models. J. Infrastruct. Syst. 2001, 7, 160-165. [CrossRef]

64. Ahmadi, M.; Cherqui, F.; de Massiac, J.-C.; Le Gauffre, P. Influence of available data on sewer inspection program efficiency. Urban Water J. 2013, 11, 641-656. [CrossRef]

65. Bundesministerium für Verkehr, Bau und Stadtentwicklung. Arbeitshilfen Abwasser-Planung, Bau und Betrieb von abwassertechnischen Anlagen in Liegenschaften des Bundes. 2015. Available online: http:/ / www.arbeitshilfen-abwasser.de/html/index.html (accessed on 24 October 2016).

66. Deutsche Vereinigung für Wasserwirtschaft, Abwasser und Abfall e.V. Arbeitsblatt DWA-A 118: Hydraulische Bemessung und Nachweis von Entwässerungssystemen; DWA: Hennef, Germany, 2006.

67. Wolf, M.; Braunschmidt, S.; Rabe, T.; Sympher, K.J. KANSAS Verbundvorhaben-Entwicklung Einer Ganzheitlichen Kanalsanierungsstrategie für Stadtentwässerungsnetze Deutschlands; Leitfaden: München, Germany, 2005.

68. Bund/Länder-Arbeitsgemeinschaft Wasser (LAWA). Leitlinien zur Durchführung Dynamischer Kostenvergleichsrechnungen (KVR-Leitlinien), 8th ed.; DWA: Hennef, Germany, 2012.

69. Mareschal, B. Weight stability intervals in multicriteria decision aid. Eur. J. Oper. Res. 1988, 33, 54-64. [CrossRef]

70. Tscheikner-Gratl, F.; Sitzenfrei, R.; Kohl, B.; Pümpel, T.; Klebinder, K.; Ebner, C.; Leonhartsberger, C.; Knapp, A.; Rauch, W. An Integrated Approach to Identify the Most Efficient Solutions for the Landfill Leachate Problem. In World Environmental and Water Resources Congress 2016; Pathak, C.S., Reinhart, D., Eds.; ASCE Press: Reston, VA, USA, 2016; pp. 11-22.

71. Huang, J.-J.; Tzeng, G.-H.; Liu, H.-H. A Revised VIKOR Model for Multiple Criteria Decision Making-The Perspective of Regret Theory. In Cutting-Edge Research Topics on Multiple Criteria Decision Making; Shi, Y., Wang, S., Peng, Y., Li, J., Zeng, Y., Eds.; Springer: Berlin/Heidelberg, Germany, 2009; pp. 761-768.

72. Cheng, S.; Chan, C.W.; Huang, G.H. Using multiple criteria decision analysis for supporting decisions of solid waste management. J. Environ. Sci. Health A 2002, 37, 975-990. [CrossRef]

73. Osman, H.; Bainbridge, K. Comparison of Statistical Deterioration Models for Water Distribution Networks. J. Perform. Constr. Facil. 2011, 25, 259-266. [CrossRef]

(C) 2017 by the authors; licensee MDPI, Basel, Switzerland. This article is an open access article distributed under the terms and conditions of the Creative Commons Attribution (CC BY) license (http:/ / creativecommons.org/licenses/by/4.0/). 